\title{
Experimental assessment of the ductility of extended end plate connections
}

\author{
Ana M. Girão Coelho ${ }^{a}$, Frans S. K. Bijlaard ${ }^{\text {b,* }}$, Luís Simões da Silva ${ }^{c}$ \\ a Department of Civil Engineering, Polytechnic Institute of Coimbra, Rua Pedro Nunes, 3030-199 Coimbra, Portugal \\ ${ }^{\mathrm{b}}$ Faculty of Civil Engineering and Geosciences, Steel and Timber Structures, Delft University of Technology, PO Box 5048, 2600 GA Delft, \\ The Netherlands \\ c Department of Civil Engineering, University of Coimbra Polo II, Pinhal de Marrocos, 3030-290 Coimbra, Portugal
}

Received 19 January 2004; received in revised form 25 March 2004; accepted 25 March 2004

\begin{abstract}
An experimental investigation of eight statically loaded extended end plate moment connections was undertaken at the Delft University of Technology to provide insight into the behaviour of this joint type up to collapse. The specimens were designed to confine failure to the end plate and/or bolts without development of the full plastic moment capacity of the beam. The parameters investigated were the end plate thickness and steel grade. The results show that an increase in end plate thickness results in an increase in the connection flexural strength and stiffness and a decrease in rotation capacity. Similar conclusions are drawn for the effect of the end plate steel grade, though no major variations in the initial stiffness are observed. The failure modes involved weld failure in two test specimens, nut stripping in four tests and bolt fracture in the remaining, always after significant yielding of the end plate and bolt bending. Comparisons of the joint ductility and the corresponding equivalent $\mathrm{T}$-stub for the end plate side are drawn.
\end{abstract}

(C) 2004 Elsevier Ltd. All rights reserved.

Keywords: Ductility; End plate connections; Experimental testing; High-strength steel grade; Resistance; Rotation capacity; Steel connections; Stiffness; T-stub model

\section{Introduction}

Structural joints exhibit a distinctively nonlinear behaviour that results from a multitude of phenomena, which include elastoplastic deformations, contact, slip and separation of their elemental parts. The analysis of such behaviour is complex. For simplicity, joints can be divided into three characteristic zones, tension, compression and shear, whose deformation contributes to the overall joint response. The joint behavioural characteristics can be represented by means of a momentrotation $(M-\Phi)$ curve that defines three main properties: resistance, stiffness and rotation capacity. Historically, moment resisting joints have been designed for resistance and stiffness with little regard to rotational

\footnotetext{
${ }^{*}$ Corresponding author. Tel.: +31-15-2784581; fax: +31-152783173.

E-mail address: f.s.k.bijlaard@citg.tudelft.nl (F.S.K. Bijlaard).
}

capacity. Yet, the knowledge of the available rotation capacity of structural joints is of utmost importance for designing partial strength joints in combination with a plastic global analysis or under seismic conditions.

The research work reported in this paper focuses on the characterization of the properties of bolted beamto-column joints with an extended end plate, similar to that shown in Fig. 1(a). In this joint type, the main source of deformability is the tension zone that can be idealized by means of equivalent $\mathrm{T}$-stubs $[1,2]$, which correspond to two T-shaped elements connected through the flanges by means of one or more bolt rows. This idealization is also adopted in modern design codes, as the Eurocode 3 [3]. Fig. 1(a) identifies the T-stub that accounts for the deformation of the column flange and the end plate in bending. In this particular case, since the column flange is unstiffened, the T-stub on the column side is orientated at right angles to the end plate T-stub [2]. 


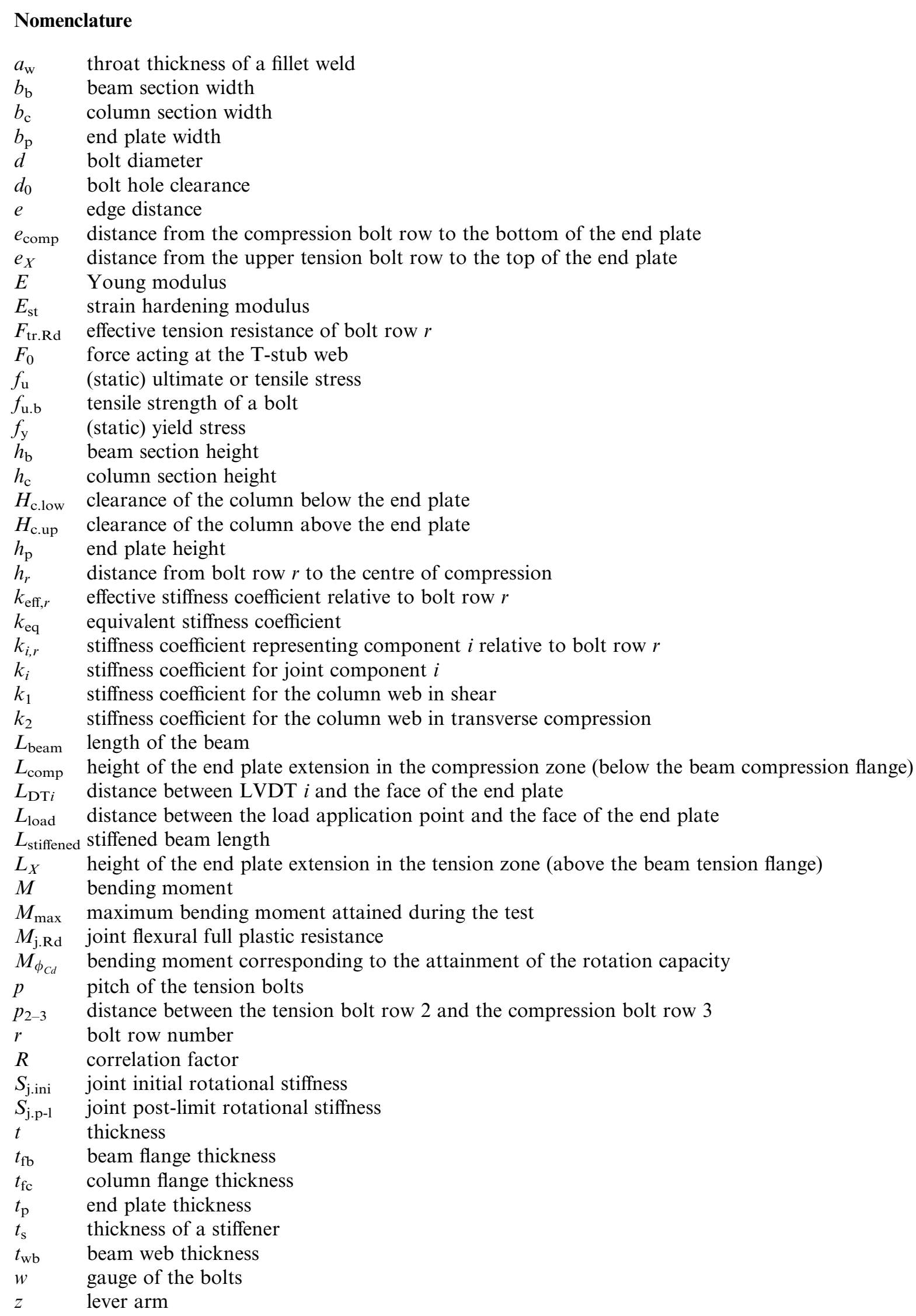




\begin{tabular}{|c|c|}
\hline$\delta_{\mathrm{b}}$ & bolt elongation \\
\hline$\delta_{\mathrm{DT} i}$ & displacement measured by LVDT DT $i$ \\
\hline$\Delta$ & axial deformation \\
\hline$\Delta_{F_{0 \text { max }}}$ & deformation value evaluated at the maximum value of the force acting at the T-stub web \\
\hline$\Delta_{F_{0 . R d}}$ & deformation value evaluated at the plastic resistance value of the force acting at the T-stub web \\
\hline$\Delta_{\mathrm{KR} . \mathrm{inf}}$ & $\begin{array}{l}\text { deformation of the end plate at the lower bound of the knee-range of the component moment-rotation } \\
\text { curve }\end{array}$ \\
\hline$\Delta_{\mathrm{KR} \text {.sup }}$ & rotation at the upper bound of the knee-range of the component moment-rotation curve \\
\hline$\varepsilon_{\mathrm{st}}$ & strain at the strain hardening point \\
\hline$\varepsilon_{\mathrm{u}}$ & ultimate strain \\
\hline$\varepsilon_{\text {uni }}$ & uniform strain \\
\hline$\phi$ & connection rotation \\
\hline$\phi_{C d}$ & rotation capacity \\
\hline$\phi_{\mathrm{KR} . \mathrm{inf}}$ & rotation at the lower bound of the knee-range of the component force-deformation curve \\
\hline $\begin{array}{l}\phi_{\mathrm{KR} . \mathrm{sup}} \\
\phi_{\max }\end{array}$ & $\begin{array}{l}\text { rotation at the upper bound of the knee-range of the component moment-rotation curve } \\
\text { maximum rotation }\end{array}$ \\
\hline$\phi_{M_{\mathrm{Rd}}}$ & maximum rotation corresponding to the joint plastic resistance \\
\hline$\phi_{M_{\max }}$ & rotation value at maximum moment \\
\hline$\Phi$ & joint rotation \\
\hline$\gamma$ & shear deformation of the column web panel zone \\
\hline$\theta_{\mathrm{b}}$ & beam rotation \\
\hline$\theta_{\text {b.el }}$ & beam elastic rotation \\
\hline$\theta_{\mathrm{c}}$ & column rotation \\
\hline$\rho_{\mathrm{y}}$ & yield ratio \\
\hline$\psi_{i}$ & component $i$ ductility index \\
\hline$\psi_{i . \mathrm{inf}}$ & $\begin{array}{l}\text { ductility index evaluated at the lower bound of the knee-range of the component force-deformation } \\
\text { curve }\end{array}$ \\
\hline$\psi$ i.sup & $\begin{array}{l}\text { ductility index evaluated at the upper bound of the knee-range of the component force-deformation } \\
\text { curve }\end{array}$ \\
\hline$\psi_{\mathrm{j}}$ & joint ductility index \\
\hline$\psi_{\mathrm{j} . \mathrm{inf}}$ & ductility index evaluated at the lower bound of the knee-range of the moment-rotation curve \\
\hline$\psi_{\text {j.sup }}$ & ductility index evaluated at the upper bound of the knee-range of the moment-rotation curve \\
\hline 0 & index related to the equivalent $\mathrm{T}$-stub \\
\hline
\end{tabular}

The models for the column and the end plate sides are different. The T-stub elements on the column flange side are generally hot rolled profiles, whilst on the end plate side such elements comprise two welded plates, the end plate and the beam flange, and a further

(a)

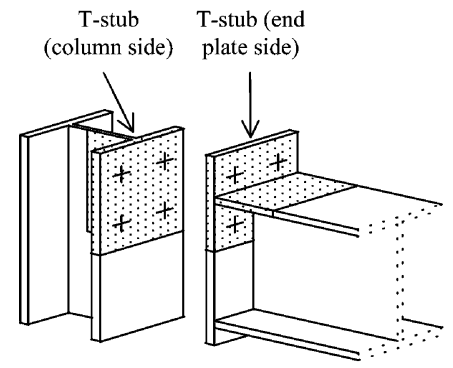

(b)

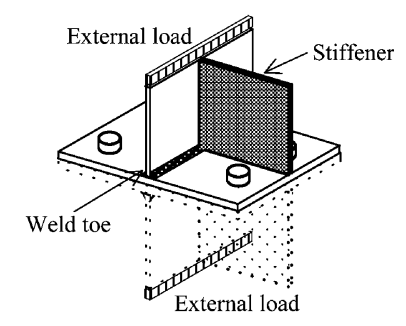

Fig. 1. Unstiffened bolted extended end plate connection. (a) T-stub identification. (b) T-stub model for the end plate side. additional stiffener that corresponds to the beam web (Fig. 1(b)). The first model has been extensively studied over the past years and was the aim of several research programmes that are reported in the literature [1,2,4-12]. The current approach to account for the behaviour of T-stubs made up of welded plates consists in a mere extrapolation of the existing rules for the other assembly type. This assumption may be erroneous and lead to unsafe estimations of the characteristic properties $[13,14]$. To deal with this problem, a research project was devised to increase the knowledge and understanding of end plate behaviour and contribute towards the improvement of its design. Simultaneously, the issue of available ductility was also addressed.

First, a series of thirty-two tests on isolated T-stub connections made up of welded plates was conducted at the Delft University of Technology. Their primary intent was to provide insight into the actual behaviour of this type of connection, failure modes and deformation 
capacity. In addition, the role of the welding and the presence of transverse stiffeners were tackled. The results of this test series are reported in [15].

As a follow up study, a second test series on full scale bolted extended end plate single-sided beam-tocolumn connections was planned. The main objective was the analysis of the ultimate behaviour of the tension zone of such a joint type and eventually the proposal of sound design rules for this elemental part within the framework of the component method $[3,16]$. The description of this test programme and results is given below. Comparisons with the code predictions [3] are also drawn.

Concerning the evaluation of the rotation capacity of end plate joints, there are several procedures reported in the literature. Zoetemeijer [17] proposes some criteria and simple empirical expressions for the estimation of a joint deformation capacity based on a series of experiments. Later, Jaspart [18] extended these criteria for inclusion in Eurocode 3 [3]. The code states that a bolted end plate joint may be assumed to have sufficient rotation capacity for plastic analysis, provided that both of the following conditions are satisfied: (i) the moment resistance of the joint is governed by the resistance of either the column flange in bending or the end plate in bending and (ii) the thickness $t$ of either the column flange or the end plate (not necessarily the same basic component as in (i)) satisfies:

$t \leq 0.36 d \sqrt{\frac{f_{\text {u.b }}}{f_{\mathrm{y}}}}$.

where $d$ is the bolt diameter, $f_{\text {u.b }}$ is the tensile strength of the bolt and $f_{\mathrm{y}}$ is the yield stress of the relevant basic component.

More recently, several researchers have developed simplified approaches based on the component method to propose expressions to quantify the overall rotation capacity. Since in many cases the most important sources of deformability in bolted joints can be idealized by means of the equivalent $\mathrm{T}$-stub in tension, special attention has been devoted to this component. Swanson [19] developed a methodology for characterization of the ductility of T-stub connections. Faella and co-workers $[10,11,20]$ set up a procedure for computation of the deformation capacity of the isolated T-stub and the overall joint. Other components have also been studied within this framework. Kuhlmann and Kuhnemund [21] performed tests on the component column web under transverse compression and proposed design rules for this component from the point of view of resistance and deformation capacity. These researchers also conducted a series of full-scale tests that are reported in [22]. The study was restricted to joints under balanced loading. The dominant component of all tests was the column web in compression. They also developed a procedure based on the component method to determine the rotation capacity of the joint.

Beg et al. [23] set up a methodology for characterization of the rotational response to include the evaluation of rotation capacity. They analysed different components, the column web, the bolts in tension, the column flange and the end plate in bending, and proposed simple expressions for evaluation of the deformation capacity based on numerical evidence.

This paper also deals with this specific issue and provides explicit experimental evidence of the rotation capacity of end plate beam-to-column joints.

\section{Description of the experimental programme}

\subsection{Test details}

The experimental programme essentially comprised four test details (two specimens for each testing type) on the above joint configuration. Two main parameters were varied in the four sets: the end plate thickness, $t_{\mathrm{p}}$ and the end plate steel grade. The specimens were fabricated from one column/beam set, as detailed in Table 1. The steel grade specified for the beams was S355. Unfortunately, due to a laboratory factual error, steel grade S235 was ordered instead. This brought a problem in terms of the beam resistance that was naturally lower than expected. Therefore, for the critical cases, the beam flanges were strengthened with continuous plates in order to increase the beam flange thickness and minimize the chance of premature failure. End plates were connected to the beam-ends by full-strength $45^{\circ}$-continuous fillet welds. The fillet welds were done in the shop in a down-hand position. The procedure involved manual metal arc welding in

Table 1

Details of the test specimens

\begin{tabular}{|c|c|c|c|c|c|c|c|}
\hline \multirow[t]{2}{*}{ Test ID } & \multirow[t]{2}{*}{ Number } & \multicolumn{2}{|l|}{ Column } & \multicolumn{2}{|l|}{ Beam } & \multicolumn{2}{|c|}{ End plate } \\
\hline & & Profile & Steel grade & Profile & Steel grade & $t_{\mathrm{p}}(\mathrm{mm})$ & Steel grade \\
\hline FS1 & 2 & HE340M & S355 & IPE300 & S235 & 10 & S355 \\
\hline FS2 & 2 & HE340M & S355 & IPE300 & S235 & 15 & S355 \\
\hline FS3 & 2 & HE340M & S355 & IPE300 & S235 & 20 & S355 \\
\hline FS4 & 2 & HE340M & S355 & IPE300 & S235 & 10 & S690 \\
\hline
\end{tabular}




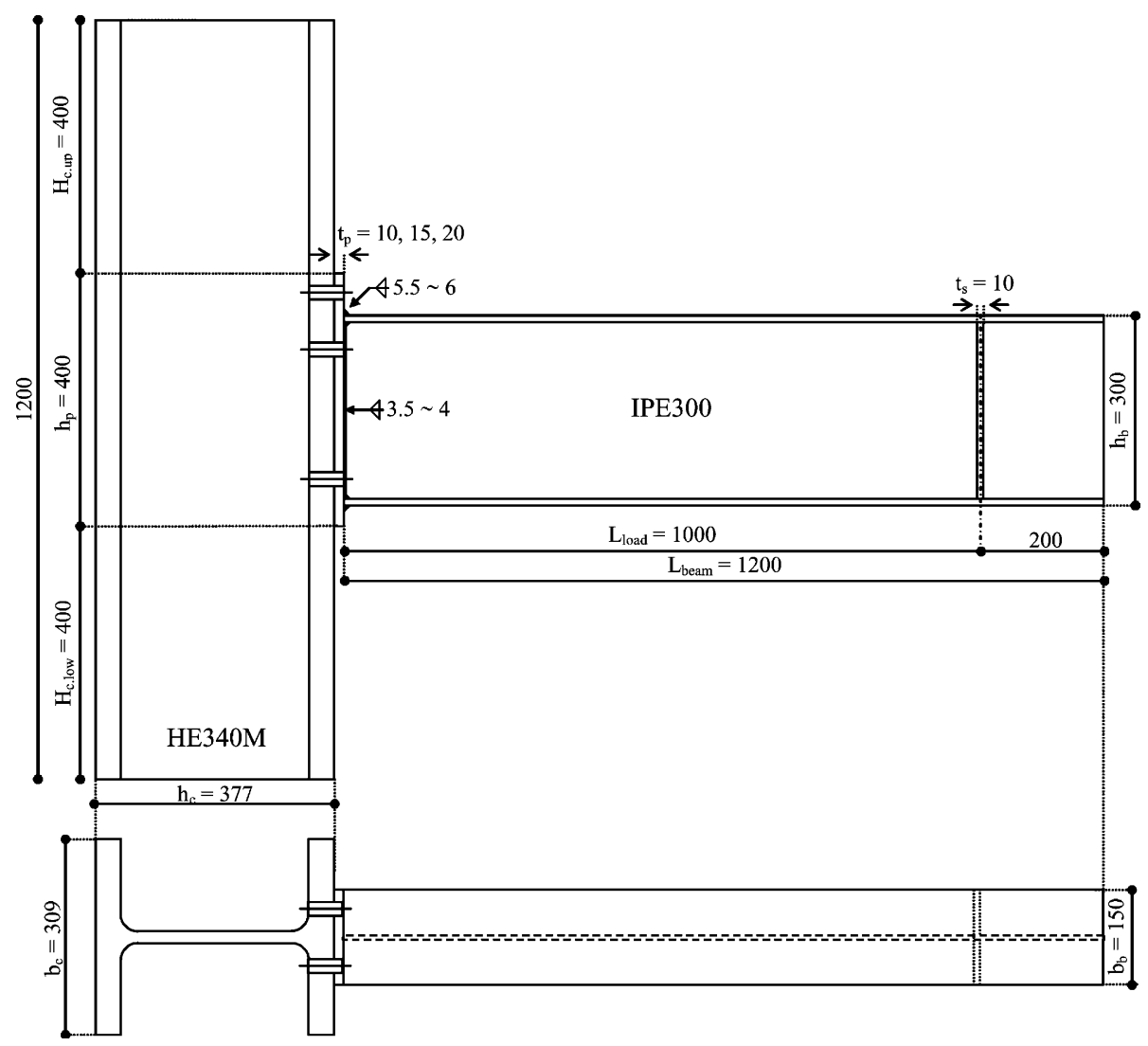

Fig. 2. Geometry of the specimens (dimensions in [mm]).

which consumable electrodes were used. Basic, soft, low hydrogen electrodes have been used in the process. Hand tightened full-threaded M20 grade 8.8 bolts in 22 $\mathrm{mm}$ drilled holes were employed in all sets. Two different batches of bolts were employed. The first batch of bolts were employed in tests FS1a-b, FS2a-b and FS3a in both tension and compression zones; the second batch of bolts were used to fasten the end plate and the beam in the tension zone in the remaining tests.

The geometry of the specimens is depicted in Figs. 2, 3. The column had a section profile HE340M that was chosen so that it behaves almost as a rigid element. In addition, for the available column, the clearance above and below the end plate was less than $400 \mathrm{~mm}$. However, since this is a rigid column, this limitation proved not to be severe. Regarding the joint geometry, the top bolt row corresponds to specimen WT7_M20 (refer to [15]) from the former test series on isolated T-stubs. This specimen comprised two plates of $10.0 \mathrm{~mm}$ thickness that were welded together by means of a continuous $45^{\circ}$-fillet weld with similar plate characteristics. Two snug-tightened M20 grade 8.8 bolts fastened the T-stub elements. All end plate specimens were designed complying with the Eurocode 3 requirements [3] so that the components end plate and bolts in the tension zone were the determining factor of collapse.

\subsection{Geometrical properties}

The actual geometry of the various connection elements was recorded before starting the test. For the various specimens the profiles and plates actual dimensions and connection geometry are summarized in Table 2. These values are given as an average value of the several measurements from each series. Table 3 indicates the bolts measurements for each test. (a)

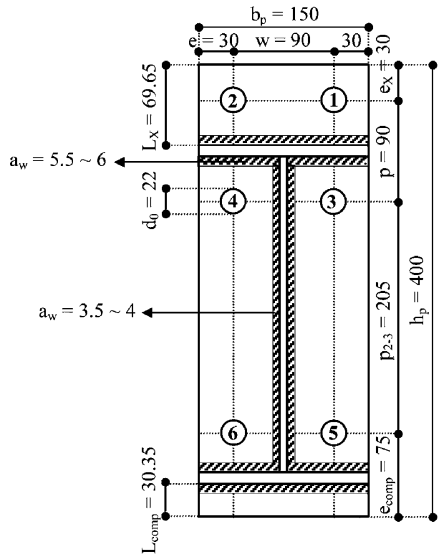

(b)

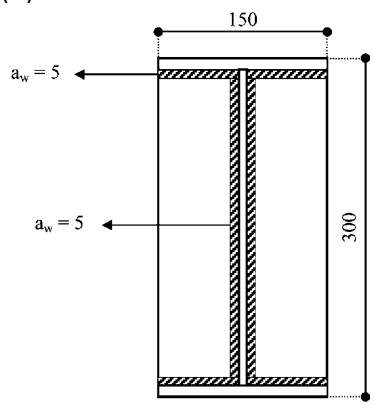

Fig. 3. Details of the specimens (dimensions in [mm]). (a) Detail of the end plate. (b) Detail of the stiffener. 
Table 2

Actual geometry of the connection (dimensions in [mm])

\begin{tabular}{|c|c|c|c|c|c|c|c|c|c|c|c|}
\hline \multirow[t]{2}{*}{ Test ID } & \multicolumn{5}{|c|}{ Column profile } & \multicolumn{6}{|c|}{ Beam profile } \\
\hline & $h_{\mathrm{c}}$ & $b_{\mathrm{c}}$ & $t_{\mathrm{fc}}$ & $H_{\text {c.up }}$ & $H_{\text {c.low }}$ & $h_{\mathrm{b}}$ & $b_{\mathrm{b}}$ & $t_{\mathrm{fb}}$ & $t_{\mathrm{wb}}$ & $L_{\text {beam }}$ & $L_{\text {load }}$ \\
\hline FS1 & 376.00 & 307.50 & 40.21 & 175.00 & 219.00 & 300.45 & 150.50 & 10.76 & 7.20 & 1200.00 & 1002.50 \\
\hline FS2 & 376.00 & 307.50 & 40.21 & 174.50 & 219.50 & 301.40 & 149.60 & 10.67 & 7.01 & 1200.38 & 1000.25 \\
\hline FS3 & 376.00 & 307.50 & 40.21 & 177.50 & 26.50 & 301.46 & 149.75 & 10.57 & 7.03 & 1191.50 & 992.63 \\
\hline FS4 & 376.00 & 307.50 & 40.21 & 174.50 & 219.50 & 300.66 & 149.54 & 11.86 & 7.03 & 1218.75 & 991.88 \\
\hline
\end{tabular}

Test ID Stif. $\quad$ End plate and connection geometry

\begin{tabular}{|c|c|c|c|c|c|c|c|c|c|c|c|}
\hline & $t_{\mathrm{s}}$ & $h_{\mathrm{p}}$ & $b_{\mathrm{p}}$ & $t_{\mathrm{p}}$ & $e$ & $w$ & $e_{X}$ & $L_{X}$ & $p$ & $p_{2-3}$ & $e_{\text {comp }}$ \\
\hline FS1 & 10.76 & 401.04 & 149.84 & 10.40 & 30.01 & 89.91 & 29.90 & 69.35 & 90.03 & 205.90 & 76.45 \\
\hline $\mathrm{FS} 2$ & 10.50 & 400.84 & 149.41 & 15.01 & 29.76 & 89.89 & 30.10 & 69.30 & 89.98 & 205.04 & 75.44 \\
\hline FS3 & 10.46 & 401.40 & 150.47 & 20.02 & 30.27 & 89.93 & 29.74 & 68.90 & 90.14 & 204.84 & 76.82 \\
\hline FS4 & 10.42 & 401.69 & 149.76 & 10.06 & 29.94 & 89.88 & 29.83 & 69.86 & 89.95 & 205.28 & 76.13 \\
\hline
\end{tabular}

\subsection{Mechanical properties}

\subsubsection{Tension tests of the structural steel}

The test programme included two different steel grades for the end plate: S355 and S690. According to the European Standards EN 10025 [24] and EN 10204 [25], the steel qualities are S355J0 (ordinary steel) and
N-A-XTRA M70 (high-strength steel for plates), respectively. For the beam profile, steel grade S235JR was ordered. Table 4 summarizes the chemical composition for the different steel grades.

The coupon tension testing of the structural steel material was performed according to the RILEM procedures [26]. The average characteristics are set out in

Table 3

Bolt hole clearance and length (dimensions in [mm])

\begin{tabular}{|c|c|c|c|c|c|c|c|c|}
\hline Test ID & & & $\# 1$ & $\# 2$ & $\# 3$ & $\# 4$ & $\# 5$ & $\# 6$ \\
\hline \multirow{4}{*}{ FS1a } & \multirow{4}{*}{ Bolt length } & $d_{0}$ & 21.93 & 21.98 & 21.98 & 21.75 & 21.98 & 21.93 \\
\hline & & Initial & 94.00 & 94.00 & 94.10 & 94.25 & 93.00 & 92.90 \\
\hline & & Hand-tightening & 94.00 & 94.00 & 94.10 & 94.25 & 93.10 & 93.00 \\
\hline & & After collapse & 94.65 & 94.40 & 94.50 & 94.90 & 93.00 & 93.10 \\
\hline \multirow{4}{*}{ FS1b } & \multirow{4}{*}{ Bolt length } & $d_{0}$ & 22.05 & 22.00 & 22.03 & 22.05 & 22.10 & 21.90 \\
\hline & & Initial & 94.00 & 94.25 & 94.40 & 94.05 & 93.15 & 93.20 \\
\hline & & Hand-tightening & 94.00 & 94.25 & 94.40 & 94.05 & 93.15 & 93.20 \\
\hline & & After collapse & 94.95 & 96.00 & 95.40 & 94.85 & 93.00 & 93.15 \\
\hline \multirow{4}{*}{ FS2a } & \multirow{4}{*}{ Bolt length } & $d_{0}$ & 21.93 & 22.08 & 22.00 & 22.08 & 22.03 & 22.03 \\
\hline & & Initial & 94.00 & 93.90 & 94.20 & 93.85 & 92.90 & 92.90 \\
\hline & & Hand-tightening & 94.02 & 93.94 & 94.20 & 93.85 & 92.94 & 92.96 \\
\hline & & After collapse & 95.70 & 96.18 & 102.06 & 96.62 & 93.24 & 93.78 \\
\hline \multirow{4}{*}{$\mathrm{FS} 2 \mathrm{~b}$} & \multirow{4}{*}{ Bolt length } & $d_{0}$ & 22.00 & 21.93 & 22.00 & 21.98 & 22.00 & 21.95 \\
\hline & & Initial & 93.90 & 94.30 & 93.90 & 94.12 & 92.86 & 92.78 \\
\hline & & Hand-tightening & 93.90 & 94.40 & 93.90 & 94.12 & 92.94 & 92.90 \\
\hline & & After collapse & 95.16 & 97.02 & 101.30 & 96.52 & 93.28 & 93.04 \\
\hline \multirow{4}{*}{ FS3a } & \multirow{4}{*}{ Bolt length } & $d_{0}$ & 22.95 & 22.88 & 22.95 & 22.98 & 23.03 & 22.93 \\
\hline & & Initial & 94.04 & 94.00 & 93.74 & 94.10 & 93.16 & 62.90 \\
\hline & & Hand-tightening & 94.10 & 94.00 & 93.80 & 94.16 & 93.16 & 92.90 \\
\hline & & After collapse & 95.56 & 95.10 & 96.04 & 96.12 & 93.48 & 93.44 \\
\hline \multirow{4}{*}{$\mathrm{FS} 3 \mathrm{~b}$} & \multirow{4}{*}{ Bolt length } & $d_{0}$ & 22.05 & 21.90 & 22.00 & 22.03 & 21.95 & 22.03 \\
\hline & & Initial & 92.54 & 92.52 & 92.56 & 92.50 & 92.78 & 93.14 \\
\hline & & Hand-tightening & 92.54 & 92.52 & 92.56 & 92.50 & 93.00 & 93.14 \\
\hline & & After collapse & 95.30 & 95.00 & 95.25 & 99.22 & 93.24 & 93.24 \\
\hline \multirow{4}{*}{ FS4a } & \multirow{4}{*}{ Bolt length } & $d_{0}$ & 22.08 & 22.00 & 22.05 & 21.93 & 22.00 & 22.05 \\
\hline & & Initial & 92.46 & 92.45 & 92.54 & 92.52 & 92.70 & 92.68 \\
\hline & & Hand-tightening & 92.50 & 92.48 & 92.56 & 92.54 & 92.74 & 92.70 \\
\hline & & After collapse & 94.40 & 93.94 & 99.62 & 102.62 & 93.06 & 93.10 \\
\hline \multirow{4}{*}{ FS4b } & \multirow{4}{*}{ Bolt length } & $d_{0}$ & 22.03 & 22.08 & 21.98 & 22.00 & 21.98 & 22.03 \\
\hline & & Initial & 92.40 & 92.38 & 92.32 & 92.38 & 93.04 & 93.06 \\
\hline & & Hand-tightening & 92.42 & 92.40 & 92.34 & 92.42 & 93.06 & 93.08 \\
\hline & & After collapse & 94.16 & 94.82 & 100.94 & 100.26 & 93.26 & 93.38 \\
\hline
\end{tabular}


Table 4

Chemical composition of the structural steels according to the European standards

\begin{tabular}{llllllll}
\hline \% maximum & $\mathrm{C}$ & $\mathrm{Mn}$ & $\mathrm{Si}$ & $\mathrm{P}$ & $\mathrm{S}$ & $\mathrm{N}$ & $\mathrm{CEV}$ \\
\hline S235JR & 0.17 & 1.40 & - & 0.045 & 0.045 & 0.012 & 0.35 \\
S355J0 & 0.20 & 1.60 & 0.55 & 0.040 & 0.045 & 0.009 & 0.40 \\
N-A-XTRA M70 & 0.20 & 1.60 & 0.80 & 0.020 & 0.010 & - & 0.48 \\
\hline
\end{tabular}

Table 5

Average characteristic values for the structural steels

\begin{tabular}{lllllllllll}
\hline Specimen & & Steel grade & $E(\mathrm{MPa})$ & $E_{\mathrm{st}}(\mathrm{MPa})$ & $f_{\mathrm{y}}(\mathrm{MPa})$ & $f_{\mathrm{u}}(\mathrm{MPa})$ & $\rho_{\mathrm{y}}$ & $\varepsilon_{\mathrm{st}}$ & $\varepsilon_{\mathrm{uni}}$ & $\varepsilon_{\mathrm{u}}$ \\
\hline End plate & $t_{\mathrm{p}}=10$ & $\mathrm{~S} 355$ & 209856 & 2264 & 340.12 & 480.49 & 0.708 & 0.015 & 0.224 & 0.361 \\
& $t_{\mathrm{p}}=15$ & $\mathrm{~S} 355$ & 208538 & 2901 & 342.82 & 507.85 & 0.675 & 0.020 & 0.198 & 0.475 \\
& $t_{\mathrm{p}}=20$ & $\mathrm{~S} 355$ & 208622 & 2771 & 342.62 & 502.59 & 0.682 & 0.017 & 0.196 & 0.457 \\
& $t_{\mathrm{p}}=10$ & $\mathrm{~S} 690$ & 204462 & 2495 & 698.55 & 741.28 & 0.940 & 0.014 & 0.075 & 0.174 \\
Beam & & & & & & & & & \\
& Web & $\mathrm{S} 235$ & 208332 & 1856 & 299.12 & 446.25 & 0.670 & 0.016 & 0.235 & 0.464 \\
& Flange & $\mathrm{S} 235$ & 209496 & 1933 & 316.24 & 462.28 & 0.684 & 0.016 & 0.235 & 0.299 \\
\hline
\end{tabular}

Table 5. In this table the values for the Young modulus, $E$, the strain hardening modulus, $E_{\mathrm{st}}$, the static yield and tensile stresses, $f_{\mathrm{y}}$ and $f_{\mathrm{u}}$, the yield ratio, $\rho_{\mathrm{y}}=f_{\mathrm{y}} / f_{\mathrm{u}}$, the strain at the strain hardening point, $\varepsilon_{\mathrm{st}}$, the uniform strain, $\varepsilon_{\mathrm{uni}}$, and the ultimate strain, $\varepsilon_{\mathrm{u}}$ are given. The stress values indicated in the table correspond to the static stresses, which are the stress values obtained at zero strain rate, i.e. during a hold on of the deformation driven experiment. It has been observed that the static stresses were reached after a hold on of circa $1 \mathrm{~min}$. The total hold on lasted for $3 \mathrm{~min}$. The yield ratio gives an idea on the material ductility. Gioncu and Mazzolani suggest that a good ductility is ensured if $0.5 \leq \rho_{\mathrm{y}} \leq=0.7$ [27]. High strength steel grades with $\rho_{\mathrm{y}}>0.9$ show a rather poor structural ductility [27]. That is the case of the steel grade S690 (Table 5). In the authors' opinion, these values are rather conservative. Eurocode 3 [3] indicates that a good material ductility is guaranteed if $\rho_{\mathrm{y}}>0.83$ (recommended value for steel grades up to S460). The assurance of a good material ductility does not necessarily imply that the whole structure is ductile. The structural ductility depends on the yield ratio but especially on the structural discontinuities, such as welds, bolt holes, etc.

\subsubsection{Tension tests on the bolts}

Two different batches of bolts were used in the experiments. Having performed tests from series FS1, FS2 and test FS3a, it was decided to use a different batch of bolts, from another manufacturer as explained later in the text. Three machined bolts from each group were tested in tension in order to determine the mechanical properties of the bolt material, in accordance with ISO 898-1999(E) [28]. The average properties are set out in Table 6.
Table 6

Average characteristic values for the bolts

\begin{tabular}{lllll}
\hline Batch & $E(\mathrm{MPa})$ & $f_{\mathrm{y}}(\mathrm{MPa})$ & $f_{\mathrm{u}}(\mathrm{MPa})$ & $\varepsilon_{\mathrm{u}}$ \\
\hline 1 & 223166 & 857.33 & 913.78 & 0.272 \\
2 & 222982 & 854.31 & 916.81 & 0.231 \\
\hline
\end{tabular}

\subsection{Test arrangement and instrumentation}

The main features of the test apparatus are illustrated in Fig. 4(a, b). With reference to the T arrangement depicted in Figs. 2, 3, the actual connection was rotated $180^{\circ}$ for practical reasons. The column was bolted to a reaction wall. The reader should bear in mind that the goal of these tests was the study of the end plate in the tension zone and therefore it had to be ensured that the column was not governing any failure mode.

The load was applied by a $400 \mathrm{kN}$ testing machine (hydraulic jack with maximum piston stroke of \pm 200 $\mathrm{mm}$ ), through a purpose-built device (Fig. 4(c)) that was clamped to the beam at $200 \mathrm{~mm}$ from the free end. In order to prevent lateral torsional buckling of the beam with the course of loading, a beam guidance device near the loading point had to be provided. For that purpose, a special device located at $250 \mathrm{~mm}$ from the load point was attached to the specimens (Fig. 4(a, b)).

The length of the beam was chosen to ensure a realistic stress pattern developed at the connection, on one hand, and that fracture of the several specimens, i.e. ultimate load, was attained with the specific testing machine.

The instrumentation plan is described in Figs. 5-7 below. The primary requirements of the instrumentation were the measurement of the applied load, the relevant displacements of the connection (e.g. vertical displacement of the beam, horizontal displacement of 
(a)

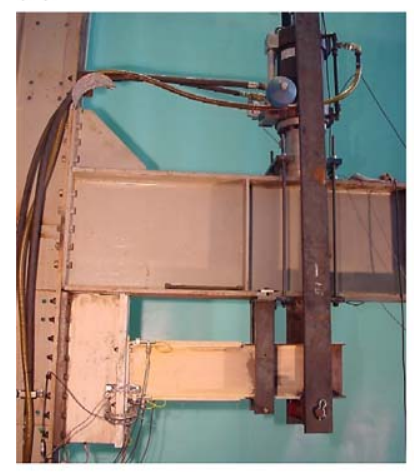

(b)

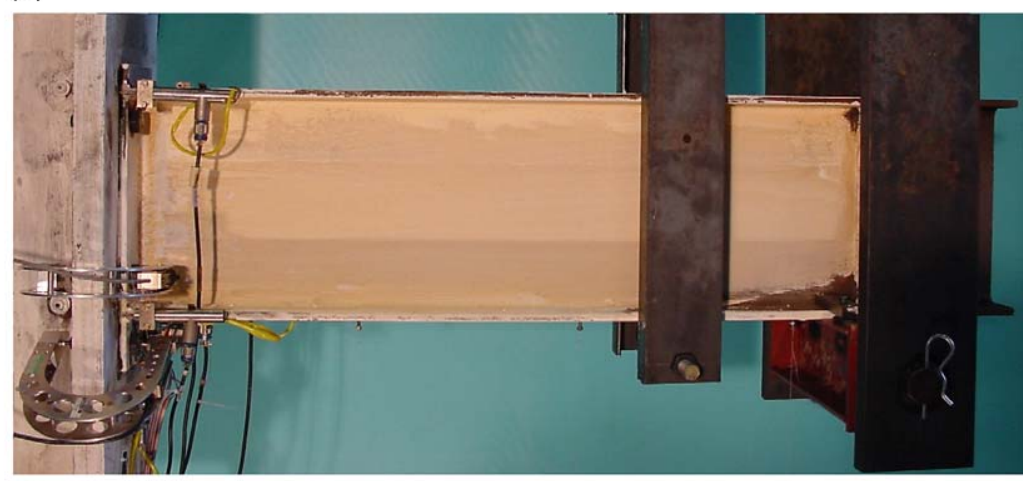

(c)
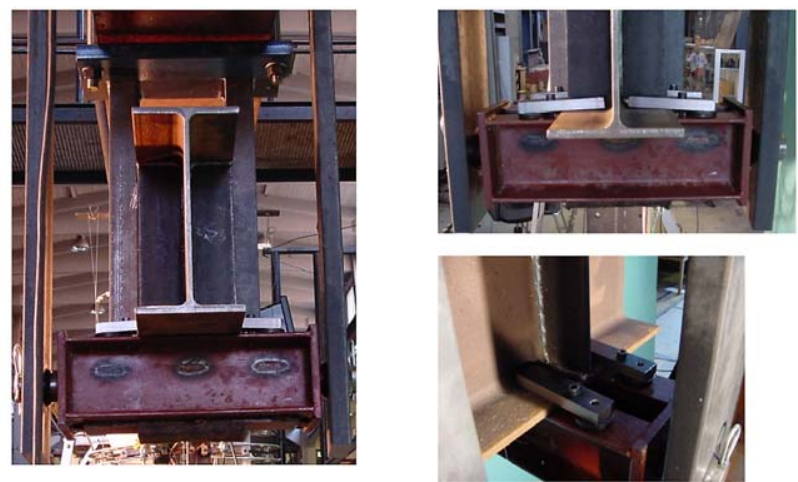

Fig. 4. Equipment and test specimen. (a) Test apparatus (illustration with specimen FS2a). (b) Detail of the beam and connection zone (illustration with specimen FS1a). (c) Detail of the load application device.

the assembly end plate-tensile beam flange) and bolt elongation. The displacements were measured by means of Linear Variable Displacement Transducers (LVDTs), located as indicated in Fig. 5. The bolts deformations were measured with special measuring brackets, MBs (horseshoe device). These devices were only attached to the bolts on the tension side and were removed before collapse to prevent damage to these devices due to bolt failure. Finally, strain gauges, SGs, TML (maximum strain $21000 \mu \mathrm{m} / \mathrm{m}$ ) were added to the end plate (back side) in the tension zone to provide insight into the strain distribution in this zone (Fig. 7(a)). In addition, the specimens were provided with strain gauges at the top of the tension beam flange (Fig. 7(b)).

For good comparison of results, all specimens used the same arrangement for the location of the strain gauges and measuring devices.

\subsection{Testing procedure}

Before installation of the specimens into the testing rig, the dimensions of the plates were recorded and the bolts were hand-tightened and measured. The specimens were then placed into the machine and aligned. The bolts were fastened by using an ordinary spanner $\left(45^{\circ}\right.$ turn) and measured.
In order to sketch the yield line patterns the specimens were painted with chalk. The measurement devices and strain gauges were then connected. Electronic records started and all the equipment was verified.

The specimens were subjected to monotonic tensile force, which was applied to the beam as explained before. The tests were carried out under displacement control with a constant speed of $0.02 \mathrm{~mm} / \mathrm{s}$ up to collapse of the specimens. The test itself then started with loading of the specimen up to $2 / 3 M_{\mathrm{j} . R \mathrm{~d}}$, which corresponds to the theoretical elastic limit. $M_{\mathrm{j} . \mathrm{Rd}}$ is the full plastic moment resistance of the joint and is determined according to Eurocode 3 [3]. Complete unloading followed on and the specimen was then reloaded up to collapse. In this third phase, the test was interrupted at the load levels corresponding to $2 / 3 M_{\mathrm{j} . \mathrm{Rd}}, M_{\mathrm{j} . \mathrm{Rd}}$, at the knee-range (KR) and after this level each $6 \mathrm{~min}$, equivalent to an actuator displacement of $7.2 \mathrm{~mm}$. The knee-range of the $M-\Phi$ curve corresponds to the transition from the stiff to the soft part. The hold on of the test lasted for $3 \mathrm{~min}$ and intended to record the quasi-static forces.

Four collapse failure modes or a combination of those were observed in the test: (i) weld cracking, (ii) plate cracking, (iii) bolt fracture and (iv) bolt nut strip- 
$\underline{\text { Top }}$

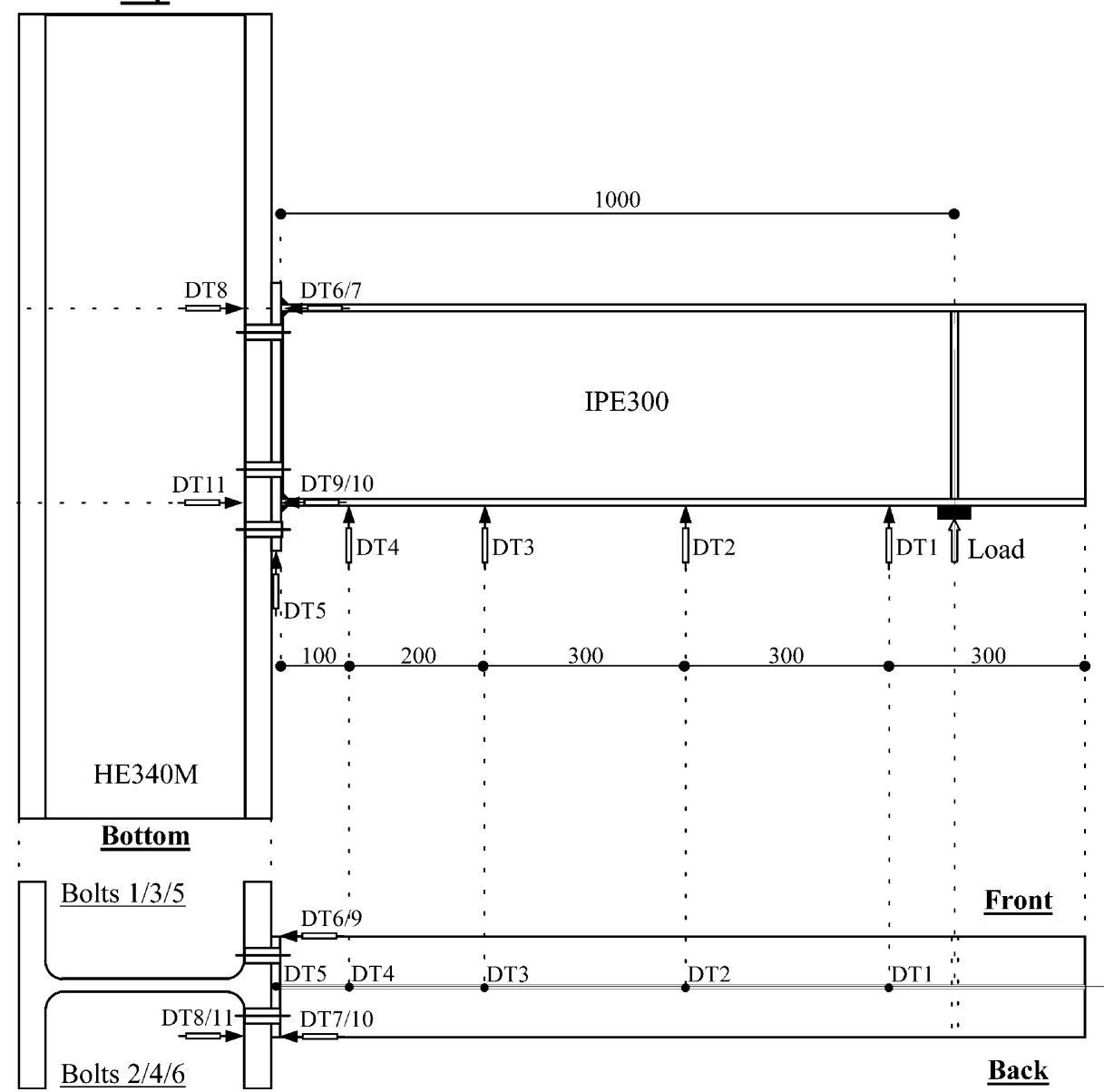

Fig. 5. Location of the displacement transducers.

ping (see Table 7). After collapse, the bolts were measured again.

\section{Test results}

\subsection{Generality}

The results presented in the following sections relate to the third phase of the tests, after elimination of slip-

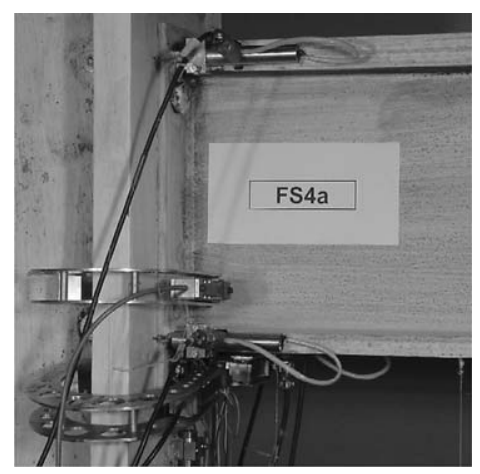

Fig. 6. MBs 1, 3 and LVDTs 6, 9 (illustration with specimen FS4a). pery and after settlement of the connecting parts. The plotted graphs refer to the applied load, displacement and strain direct readings and to the corresponding bending moment and deformations.

The bending moment, $M$, acting on the connection corresponds to the applied load, "Load" multiplied by the distance between the load application point and the face of the end plate, $L_{\text {load }}$ :

$M=$ Load $\times L_{\text {load }}$

The rotational deformation of the joint, $\Phi$, is the sum of the shear deformation of the column web panel zone, $\gamma$ and the connection rotational deformation, $\phi$ [18]. Connection rotation is defined as the change in angle between the centrelines of beam and column, $\theta_{\mathrm{b}}$ and $\theta_{\mathrm{c}}$, respectively [18]:

$\phi=\theta_{\mathrm{b}}-\theta_{\mathrm{c}}$.

In these tests, the column hardly deforms as it behaves as a rigid element. This statement will be validated later in the text. Then, both $\gamma$ and $\theta_{\mathrm{c}}$ are nought and so,

$\Phi=\phi=\theta_{\mathrm{b}}$. 
(a)
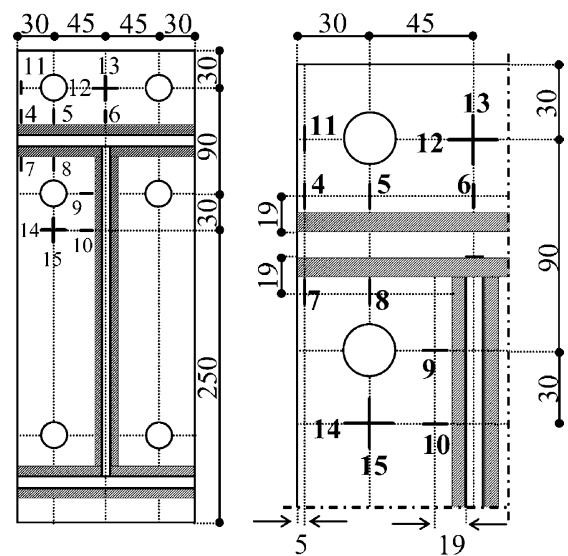

- Unidirectional strain gauges

$+x y$ strain gauges

(b)

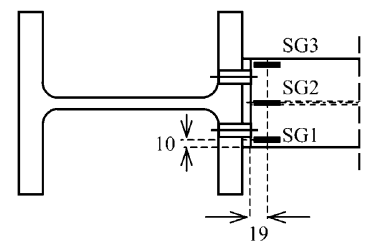

Fig. 7. Location of the strain gauges. (a) Strain gauges located at the end plate. (b) Strain gauges located at the beam.

The beam rotation is approximately given by (Fig. 5):

$$
\begin{aligned}
\theta_{\mathrm{b}} & =\arctan \frac{\delta_{\mathrm{DT} 1}}{900}-\theta_{\mathrm{b} . \mathrm{el}}=\arctan \frac{\delta_{\mathrm{DT} 2}}{600}-\theta_{\mathrm{b} . \mathrm{el}} \\
& =\arctan \frac{\delta_{\mathrm{DT} 3}}{300}-\theta_{\mathrm{b} . \mathrm{el}}=\arctan \frac{\delta_{\mathrm{DT} 4}}{100}-\theta_{\mathrm{b} . \mathrm{el}},
\end{aligned}
$$

where $\delta_{\mathrm{DT} i}$ are the vertical displacements at LVDT DT $i$ and $\theta_{\mathrm{b} . \mathrm{el}}$ is the beam elastic rotation. The above expression disregards the effect of shear deformation in the beam and assumes that the vertical displacements of the end plate are negligible, i.e. $\delta_{\mathrm{DT} 5} \approx 0$. Some differences in the results from DT4 are expected when compared to the remaining LVDTs since it is located closer to the end plate. In this region, the beam theory is not valid and the stress distribution is not smooth.

By using the above relationships, the $M-\phi$ curve of the connection can be characterized. The main features of this curve are: moment resistance, rotational stiffness and rotation capacity. In particular, for the different tests the following characteristics are assessed [29]: the knee-range of the $M-\phi$ curve, the plastic flexural resistance, $M_{\mathrm{j} . \mathrm{Rd}}$, the maximum bending moment, $M_{\max }$, the initial stiffness, $S_{\text {j.ini }}$, the post-limit stiffness, $S_{\text {j.p-1 }}$, the rotation corresponding to the maximum load level, $\phi_{M_{\max }}$ and the rotation capacity, $\phi_{C d}$ (see Fig. 8). The stiffness values are computed by means of linear regression analysis of the quasi-linear branches before and after the knee-range. To determine $S_{\mathrm{j} \text {.ini }}$, in particular, the unloading portion of the $M-\phi$ curve (phase 2 of the tests, which is not traced in the graphs) is considered.

The ductility of a joint is a property that reflects the length of the yield plateau of the $M-\phi$ response. This property can be quantified by means of an index, $\psi_{\mathrm{j}}$ that relates the maximum rotation of the joint, $\phi_{\max }$ to the rotation value corresponding to the joint plastic resistance, $\phi_{M_{\mathrm{Rd}}}[18,30,31]$ :

$\psi_{j}=\frac{\phi_{\max }}{\phi_{M_{\mathrm{Rd}}}}$

For the several examples, the index $\psi_{\mathrm{j}}$ is also evaluated. Since the experimental value of the joint plastic resistance is not easily assessed, two different resistance levels are also taken into account: the lower and upper bound for the knee-range of the $M-\phi$ curve, corresponding to $\psi_{\mathrm{j} \text {.inf }}$ and $\psi_{\mathrm{j} \text {.sup }}$, respectively. Also, two different values for $\phi_{\max }$ are considered: $\phi_{C d}$ and $\phi_{M_{\max }}$. Similar ductility index can also be defined for a single component, $\psi_{i}$, by replacing the rotation values with the axial deformation values [30,31].

A brief summary of the observed failure modes is given in Table 7 and some illustrations are given in Fig. 9. Failure occurred due to a variety of reasons, but the failure modes always involved the components end plate and bolts in the tension zone.

Table 7

Description of failure types

\begin{tabular}{ll}
\hline Test ID & Mode of failure \\
\hline FS1a & Weld failure of the assembly beam-end plate, both at the flange and web sides (Fig. 9(a)). \\
FS1b & Weld failure of the assembly beam-end plate, both at the flange and web sides and plate cracking at opposite sides (Fig. 9(b)). \\
FS2a & Nut stripping of bolt \#4 and weld failure along the whole end plate extension width but not at the inner part (Fig. 9(c)). \\
FS2b & Nut stripping of bolts \#1 and \#4 with no plate cracking or weld failure. \\
FS3a & Nut stripping of bolts \#3 and \#4 and some weld failure close to bolt \#3 but without development of a crack. \\
FS3b & Nut stripping of bolt \#3. \\
FS4a & Fracture of bolt \#4 and some weld failure at the end plate extension close to bolt \#1 but without development of a complete \\
FS4b & Frack.
\end{tabular}




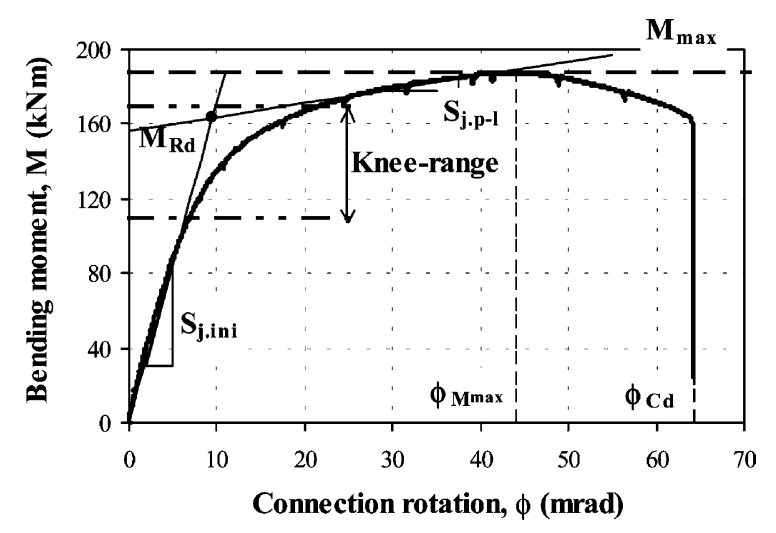

Fig. 8. Moment-rotation characteristics from tests.

\subsection{Moment-rotation curves}

As explained above, the $M-\phi$ curves for the several connections are obtained from the beam vertical displacement readings and the applied load. For illustration, Fig. 10 plots the load vs. vertical displacement of the beam for specimen FS1a. This curve can be converted into moment-"gross beam rotation" curve through application of Eqs. (2) and (5) excluding $\theta_{\mathrm{el}}$, as shown in Fig. 11(a) for the four LVDTs DT1-4. Examination of these four curves indicates a good agreement of the results obtained for DT1-3 and some deviation for DT4. These differences have already been explained earlier in the text. Therefore, the results from DT1 are kept for further analysis. If now the beam elastic deformation is subtracted from the "gross rotation" (Eq. (5)), the connection rotation can be completely characterized (Fig. 11(b)). This value is taken as equal to the beam rotation as the column rotation, $\theta_{\mathrm{c}}$, can be disregarded in comparison with $\theta_{\mathrm{b}}$ (see Fig. 12) and also because the end plate vertical deformation due to bolt hole elongation can be neglected when compared to $\delta_{\mathrm{DT} 1}$ (see Fig. 13). Note that for specimen FS1a the slippery at circa $110 \mathrm{kN}$ has to be disregarded.

The $M-\phi$ responses for the eight connection details are reported in Fig. 14. Almost identical responses are obtained for each set over the entire elastoplastic range. This proves that the test procedure and the instrumentation setup adopted for the programme was satisfactory. The main features of the eight curves are summarized in Table 8. All characteristic values are referred to the readings from LVDT DT1. In all cases, the knee-range domain of the curves is alike for the same connection detail. The maximum resistance is also similar, though in series FS1 and FS3 some differences are observed. In series FS1, experimental observations show that the welding quality in set FS1a is poor, i.e. the welding procedure resulted in a glue weld instead of a burnt-in weld. This induced premature

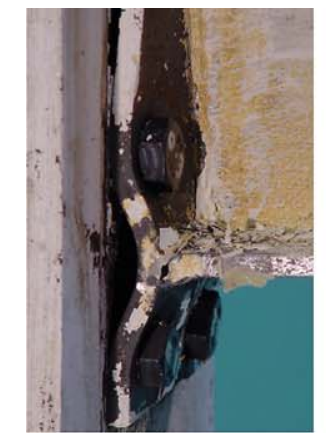

(a)

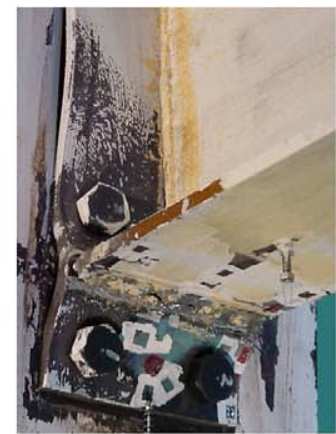

(i)

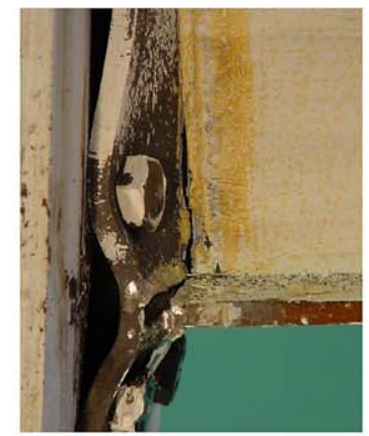

(ii)

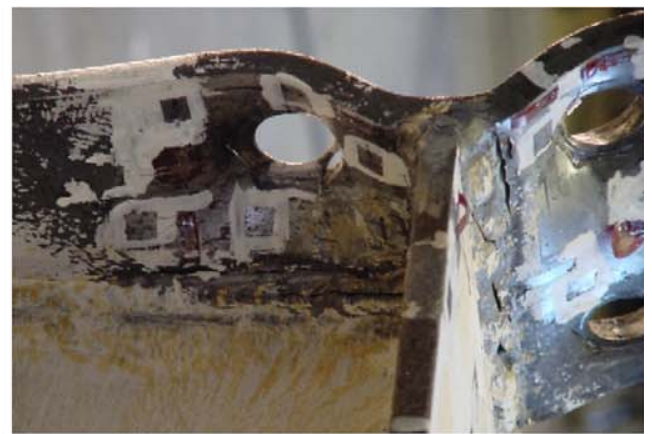

(iii)

(b)
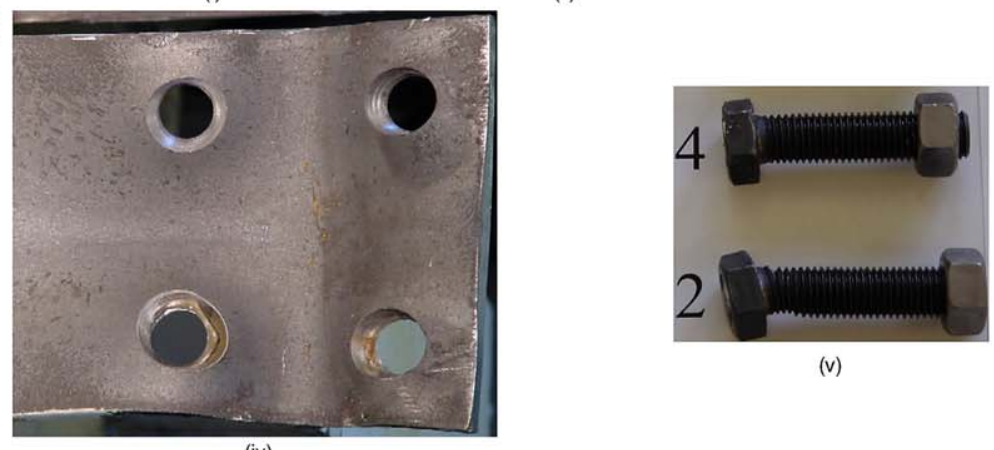

(v)

(iv)

Fig. 9. Illustration of the various failure types observed in the experiments. (a) Specimen FS1a: weld failure. (b) Specimen FS1b. (i) General view. (ii) Detail of the weld failure at the front side. (iii) Detail of the end plate cracking (extension) at the back side. (iv) Elongation of the bolt holes in the tension zone. (v) Detail of bolts \#2 and \#4 (back side) after failure (notice the bending of bolt \#2). (c) Specimen FS2a. (i) General view of the end plate. (ii) Nut stripping of bolt \#4 (column side). (iii) Detail of the weld fracture in the tension zone. (iv) Detail of tension bolts (bolt \#3 nearly fractures). (d) Specimen FS4b. (i) Bolt \#3. (ii) Bolt \#4. 
(c)

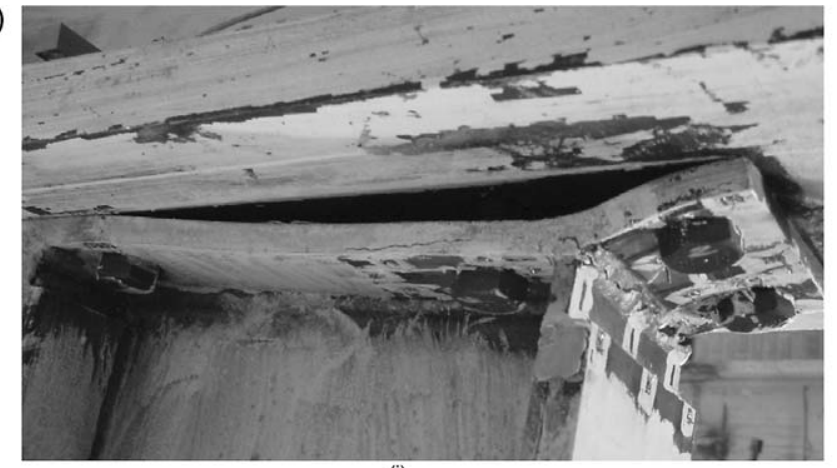

(i)

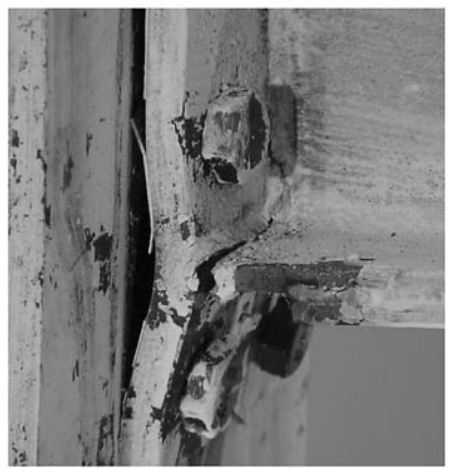

(iii)
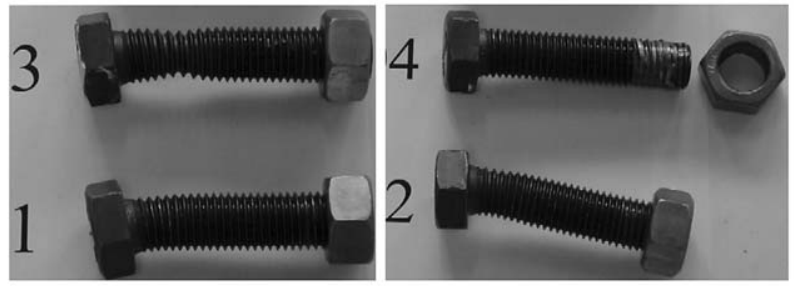

(iv)

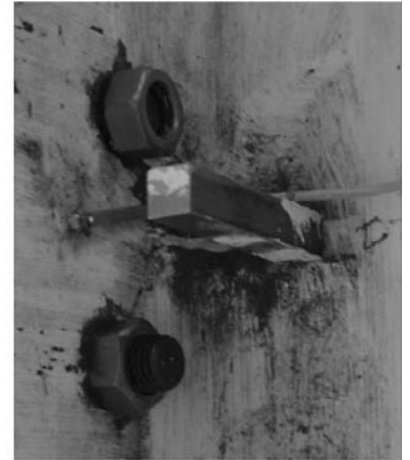

(ii)

(d)

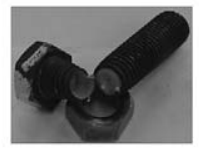

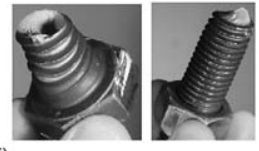

(i)

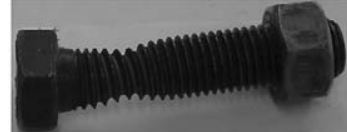

(ii)

Fig. 9 (continued)

cracking of the specimen. Regarding series FS3, the discrepancies arise because different bolts are employed in the two sets and also because there was a disturbance in test FS3a at a load level of $190 \mathrm{kN}$ that may have had some effect over the final results. In terms of rotational stiffness, some differences arise, particularly for $S_{\mathrm{j} . \text { ini }}$ in the case of series FS1 and $S_{\mathrm{j} . \mathrm{p}-1}$ for series

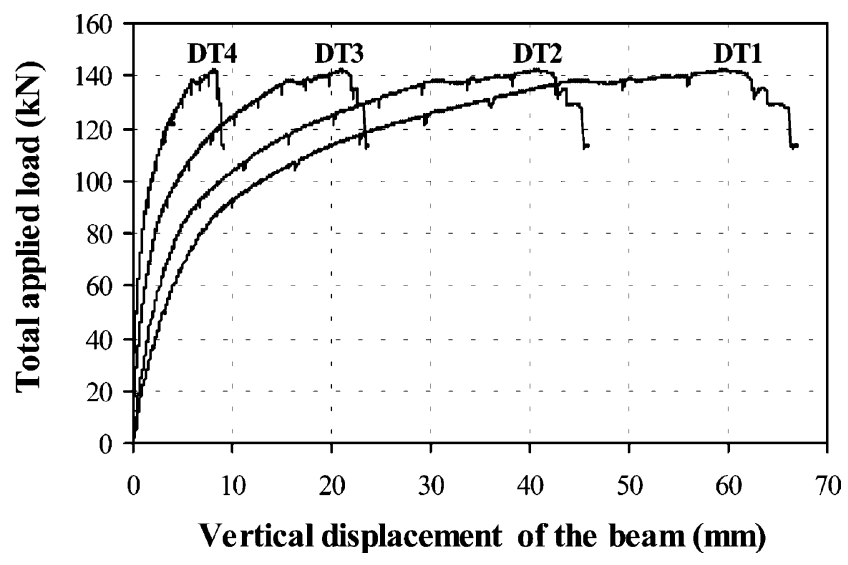

Fig. 10. Beam vertical displacement readings of LVDTs DT1-4 for specimen FS1a.
FS3. Identical values of the ratio $S_{\mathrm{j} . \text { ini }} / S_{\mathrm{j} . \mathrm{p}-1}$ are obtained for the four test types. Exception is made for joint FS3a, which shows some disturbance in the postlimit regime, and therefore the out coming results are not reliable in this domain.

Now, in terms of maximum rotation, the values at $M_{\max }$ are close for each set (again, the results for FS3a should not be relied upon in the post-limit domain), particularly for specimen FS2. Higher deviations appear for $\phi_{C d}$, especially for series FS1 and FS2. The differences that are observed in series FS1 have already been explained above. For series FS2 and FS3, $\phi_{C d}$ is not well defined since it corresponds to the beginning of final unloading of the test. No actual rupture was observed in this case. The test was stopped because the deformations were already too high and there was fear of damaging the equipment if the test went on further.

One connection from each set is now chosen for the purpose of a comparative study. In all cases, the assembly end plate-bolts is the main source of connection deformability. Fig. 15 compares the rotational behaviour of the four test types and shows an increase in resistance and rotational stiffness and a loss of rotation capacity with the end plate thickness (FS1, 
(a)

\section{ह}

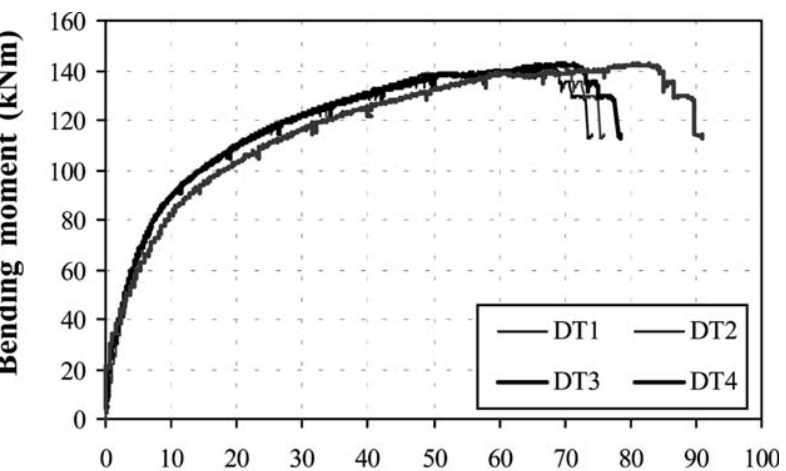

Beam rotation includ. elastic def. (mrad)

(b)

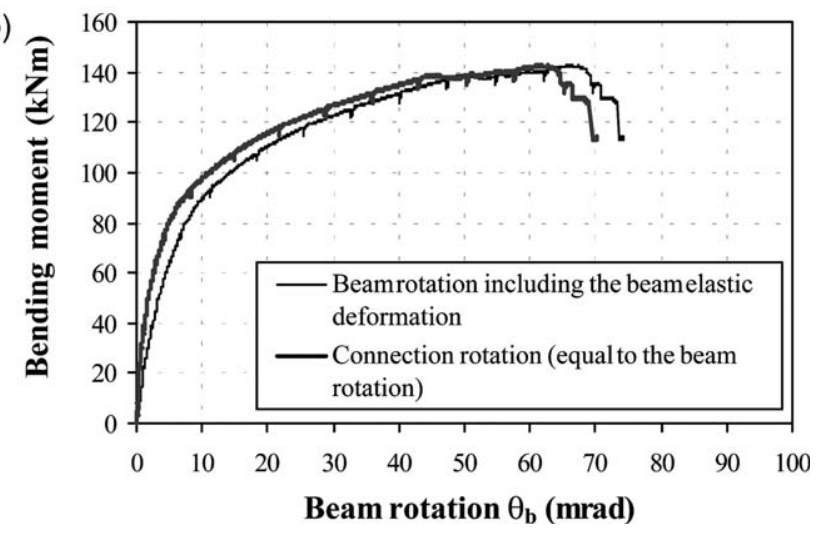

Fig. 11. Beam rotation for specimen FS1a. (a) Beam rotation computed from the displacement readings of LVDTs DT1-4 $\left(\arctan \left(\delta_{\mathrm{DT} i} / L_{\mathrm{DT} i}\right)\right)$. (b) Beam rotation computed by means of Eq. (5) from the displacement readings of LVDT DT1.

FS2 and FS3). The effect of the steel grade is identical (FS1 and FS4).

\subsection{Behaviour of the tension zone}

\subsubsection{End plate deformation behaviour}

The most significant characteristic describing the overall end plate deformation behaviour in the tension zone is the force-deformation response. The test setup does not allow for a direct measurement of the force at the component level but the information gathered from LVDTs DT9 and DT10 permits full characterization of the end plate deformation behaviour. These transducers are attached to the beam flange and they measure the gap between the end plate and the column flange (see Fig. 5). As an example, Fig. 16(a) traces the moment-gap response as obtained for DT9 and DT10 for specimens FS1b and FS4a and indicates a good agreement over the whole loading history. For comparison, Fig. 16(b) shows that these measurements are also identical for the two sets from one test type.

Fig. 17 compares the end plate deformation behaviour for the four connection details. The deformability of the end plate increases for smaller values of $t_{\mathrm{p}}$ and (a)

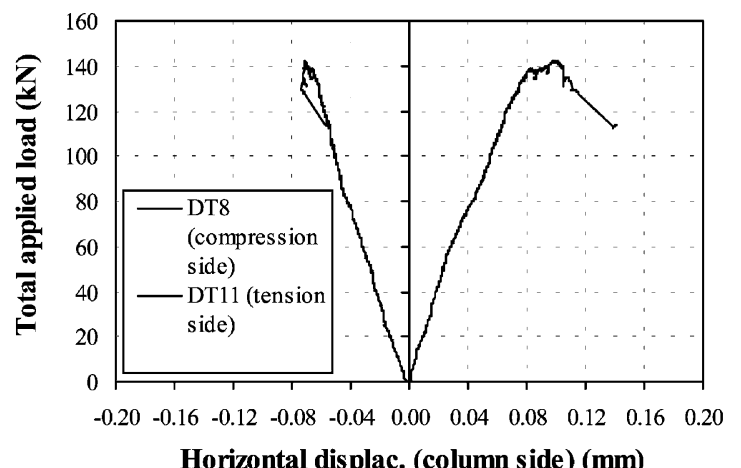

(b)

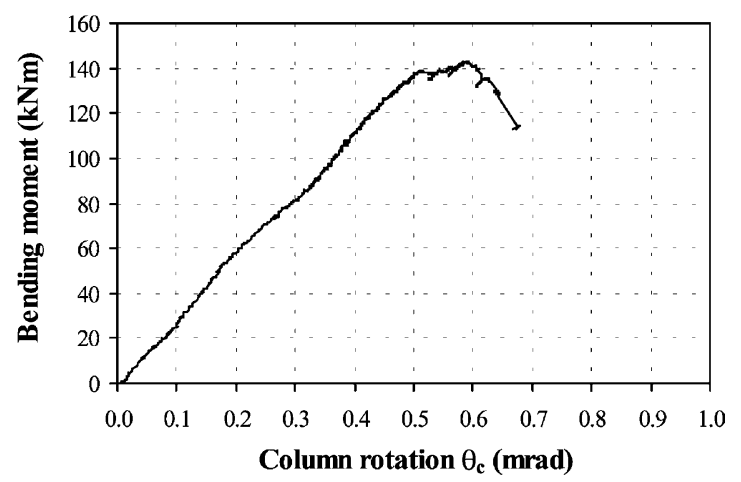

(c)

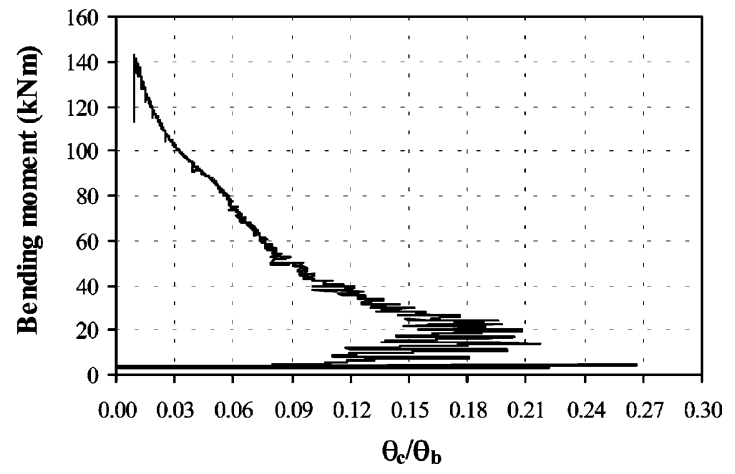

Fig. 12. Column rotation for specimen FS1a. (a) Column horizontal displacements. (b) Corresponding column rotations $\left(\theta_{\mathrm{c}}=\right.$ $\left.\arctan \left(\left(\left|\delta_{\mathrm{DT} 8}\right|+\left|\delta_{\mathrm{DT} 11}\right|\right) /\left(\mathrm{h}_{\mathrm{b}}-\mathrm{t}_{\mathrm{fb}}\right)\right)\right)$. (c) Ratio between column rotation and beam rotation.

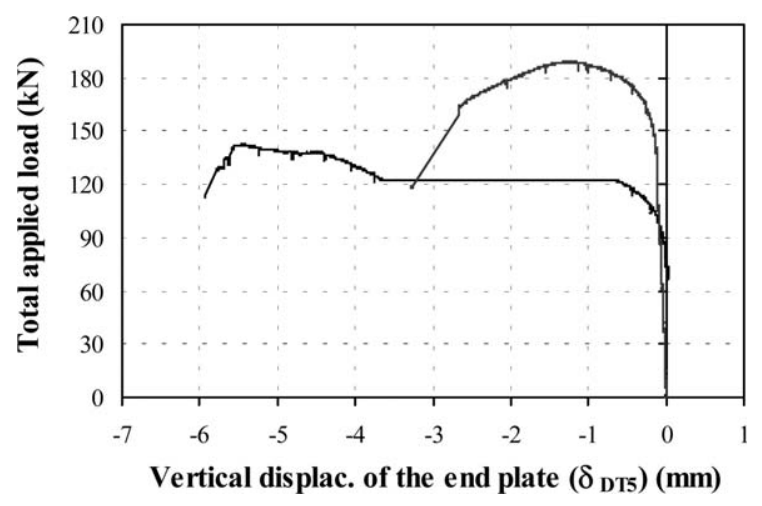

Fig. 13. End plate vertical displacement for specimens FS1a and FS4b. 
(a)

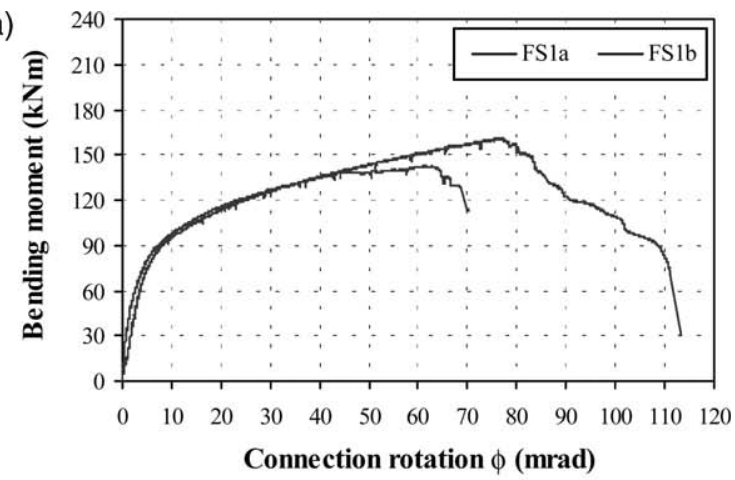

(b)

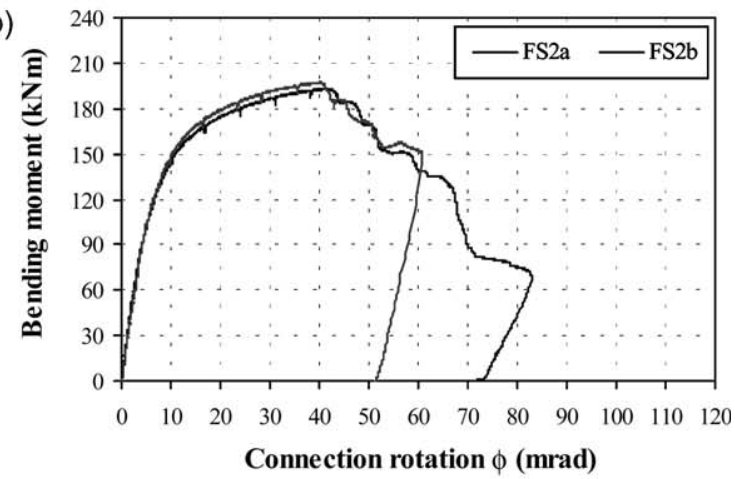

(c)

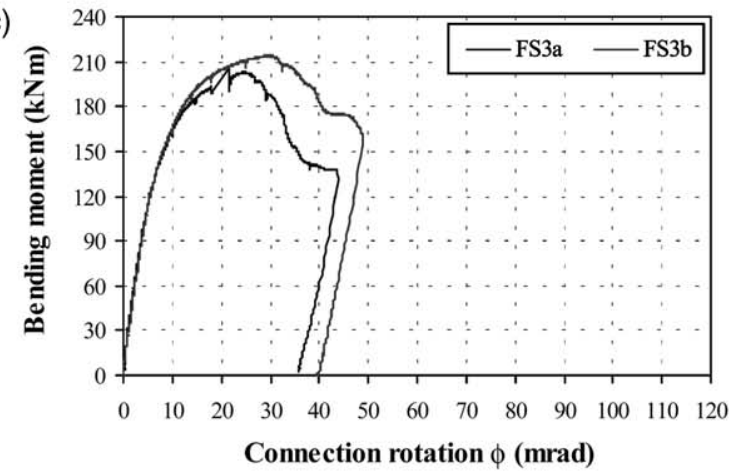

(d)

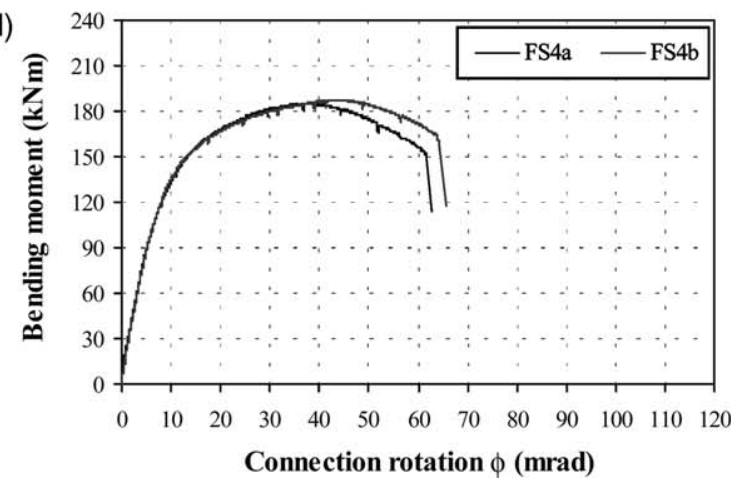

Fig. 14. Moment-rotation curves for the four test series. (a) Series FS1. (b) Series FS2. (c) Series FS3. (d) Series FS4.

lower steel grades. This behaviour is identical to the connection rotation, as expected, since the components end plate and bolts are the main sources of connection deformability. Fig. 18 illustrates the evolution of the end plate deformation response with the applied load for the specific case of FS4b and Figs. 18(d) and 19 compare the collapse conditions for the four test types.

A comparative analysis of the influence of the end plate deformability over the connection rotational behaviour is plotted in the graph of Fig. 20. For series FS2, FS3 and FS4 where the bolts mainly determine failure, either by fracture or by stripping, the shape of the curves is identical. In series FS1 where end plate cracking and weld fracture are engaged in the collapse mode, the shape of the curve is slightly different. Even so, these curves clearly demonstrate that the ratio between end plate deformation behaviour is higher for lower end plate thickness values and lower steel grades.

Finally, Fig. 21 shows an alternative procedure for computation of the connection deformation from the readings of the horizontal LVDTs, in the compression and tension zone of the end plate (e.g. specimen FS1a). As expected, the agreement between both procedures is excellent.

\subsubsection{Yield line patterns}

Fig. 22 depicts the yield line patterns of the inner tension bolt \#3 for specimens FS1b and FS2b at collapse conditions. These patterns could be sketched with the painting of the specimens with chalk. Clearly, for series FS1 the yielding of the end plate in this area spreads to the compression bolt, whilst for FS2, with a thicker plate, there is a small amount of plasticity in the end plate.

\subsubsection{Bolt elongation behaviour}

The experimental results demonstrate that the two rows of tension bolts carry unequal forces (Fig. 23): the inner tension bolts carry a larger proportion of the load than the outer bolts. This conclusion is also supported by the graphs shown in Fig. 24 that compares the ratio between the bolt elongation, $\delta_{\mathrm{b}}$ and the gap end plate-column flange. This ratio increases for the inner tension bolts. The graphs also highlight the influence of the bolt tension deformation on the overall behaviour with the increase of $t_{\mathrm{p}}$ and steel grade. This conclusion is in line with the above observations.

\section{Discussion of test results}

\subsection{Introduction}

Eurocode 3 [3] gives quantitative rules for the prediction of the joint flexural plastic resistance and initial rotational stiffness. These structural properties are evaluated below by using the actual geometrical characteristics from Table 2 and the mechanical properties from Tables 5 and 6 . Also, the recommendations on rotation capacity are verified to investigate if there is enough 
Table 8

Main characteristics of the moment-rotation curves

\begin{tabular}{|c|c|c|c|c|c|c|c|c|}
\hline \multirow[t]{2}{*}{ Test ID } & \multicolumn{3}{|c|}{ Resistance $[\mathrm{kNm}]$} & \multicolumn{3}{|c|}{ Stiffness $[\mathrm{kNm} / \mathrm{mrad}]$} & \multicolumn{2}{|c|}{ Rotation [mrad] } \\
\hline & $\begin{array}{l}\text { Knee- } \\
\text { range }\end{array}$ & $M_{\mathrm{j} . \mathrm{Rd}}$ & $M_{\max }$ & $S_{\mathrm{j} . \text { ini }}$ & $S_{\mathrm{j} \cdot \mathrm{p}-1}$ & $\begin{array}{l}\text { Ratio } \\
S_{\text {j.ini }} / S_{\text {j.p-1 }}\end{array}$ & $\phi_{M_{\max }}$ & $\phi_{C d}$ \\
\hline FS1a & $65-112$ & $\begin{array}{l}105.60 \\
\left(\phi_{M_{\mathrm{Rd}}}=5.81 \mathrm{mrad}\right)\end{array}$ & 142.76 & $\begin{array}{l}18.19 \\
\left(R^{2}=0.9717\right)\end{array}$ & $\begin{array}{l}0.84 \\
\left(R^{2}=0.9384\right)\end{array}$ & 21.55 & 61.55 & $\begin{array}{l}68.91 \\
\left(M_{\phi_{C d}}=127.71 \mathrm{kNm}\right)\end{array}$ \\
\hline FS1b & $68-120$ & $\begin{array}{l}109.30 \\
\left(\phi_{M_{\mathrm{Rd}}}=6.49 \mathrm{mrad}\right)\end{array}$ & 161.17 & $\begin{array}{l}16.84 \\
\left(R^{2}=0.9921\right)\end{array}$ & $\begin{array}{l}0.74 \\
\left(R^{2}=0.9681\right)\end{array}$ & 22.78 & 77.05 & $\begin{array}{l}111.22 \\
\left(M_{\phi_{C d}}=70.29 \mathrm{kNm}\right)\end{array}$ \\
\hline $\mathrm{FS} 2 \mathrm{a}^{\mathrm{a}}$ & $120-174$ & $\begin{array}{l}165.65 \\
\left(\phi_{M_{\mathrm{Rd}}}=7.08 \mathrm{mrad}\right)\end{array}$ & 193.06 & $\begin{array}{l}23.39 \\
\left(R^{2}=0.9925\right)\end{array}$ & $\begin{array}{l}0.84 \\
\left(R^{2}=0.8611\right)\end{array}$ & 27.93 & 41.72 & $\begin{array}{l}82.88 \\
\left(M_{\phi_{C d}}=66.00 \mathrm{kNm}\right)\end{array}$ \\
\hline $\mathrm{FS} 2 \mathrm{~b}^{\mathrm{a}}$ & $117-181$ & $\begin{array}{l}170.22 \\
\left(\phi_{M_{\mathrm{Rd}}}=7.74 \mathrm{mrad}\right)\end{array}$ & 197.31 & $\begin{array}{l}22.00 \\
\left(R^{2}=0.9968\right)\end{array}$ & $\begin{array}{l}0.92 \\
\left(R^{2}=0.8405\right)\end{array}$ & 23.91 & 40.30 & $\begin{array}{l}60.89 \\
\left(M_{\phi_{C d}}=147.93 \mathrm{kNm}\right)\end{array}$ \\
\hline $\mathrm{FS} \mathrm{a}^{\mathrm{a}}$ & $112-186$ & $\begin{array}{l}172.27 \\
\left(\phi_{M_{\mathrm{Rd}}}=7.47 \mathrm{mrad}\right)\end{array}$ & 202.91 & $\begin{array}{l}23.23 \\
\left(R^{2}=0.9905\right)\end{array}$ & $\begin{array}{l}1.81 \\
\left(R^{2}=0.8629\right)\end{array}$ & 12.82 & 25.00 & $\begin{array}{l}42.76 \\
\left(M_{\phi_{C d}}=108.16 \mathrm{kNm}\right)\end{array}$ \\
\hline $\mathrm{FS}_{3} \mathrm{~b}^{\mathrm{a}}$ & $122-200$ & $\begin{array}{l}192.66 \\
\left(\phi_{M_{\mathrm{Rd}}}=8.94 \mathrm{mrad}\right)\end{array}$ & 214.35 & $\begin{array}{l}21.56 \\
\left(R^{2}=0.9972\right)\end{array}$ & $\begin{array}{l}1.03 \\
\left(R^{2}=0.8003\right)\end{array}$ & 20.96 & 29.99 & $\begin{array}{l}48.74 \\
\left(M_{\phi_{C d}}=153.10 \mathrm{kNm}\right)\end{array}$ \\
\hline FS4a & $110-170$ & $\begin{array}{l}165.60 \\
\left(\phi_{M_{\mathrm{Rd}}}=10.24 \mathrm{mrad}\right)\end{array}$ & 185.32 & $\begin{array}{l}16.18 \\
\left(R^{2}=0.9936\right)\end{array}$ & $\begin{array}{l}0.78 \\
\left(R^{2}=0.8004\right)\end{array}$ & 20.61 & 37.70 & $\begin{array}{l}61.69 \\
\left(M_{\phi_{C d}}=150.25 \mathrm{kNm}\right)\end{array}$ \\
\hline FS4b & $110-170$ & $\begin{array}{l}163.52 \\
\left(\phi_{M_{\mathrm{Rd}}}=9.53 \mathrm{mrad}\right)\end{array}$ & 187.67 & $\begin{array}{l}17.15 \\
\left(R^{2}=0.9956\right)\end{array}$ & $\begin{array}{l}0.74 \\
\left(R^{2}=0.8681\right)\end{array}$ & 23.29 & 43.85 & $\begin{array}{l}64.24 \\
\left(M_{\phi_{C d}}=158.09 \mathrm{kNm}\right)\end{array}$ \\
\hline
\end{tabular}

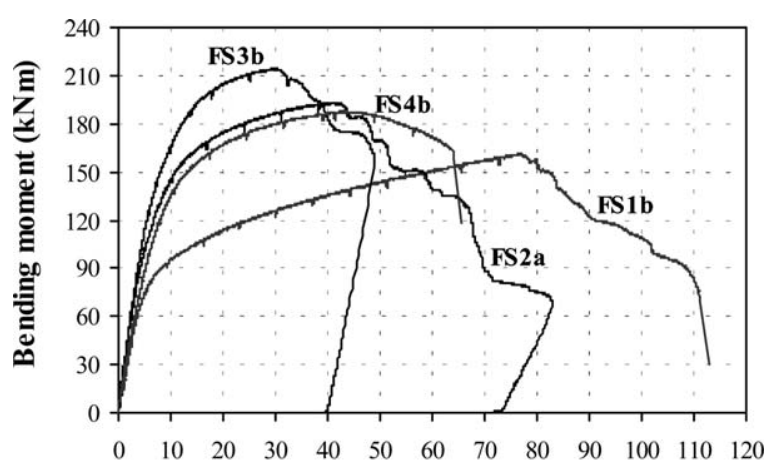

Connection rotation $\phi$ (mrad)

Fig. 15. Comparison of the moment-rotation curves for the four test series.

rotation capacity according to the code. The provisions are compared with the test results.

\subsection{Plastic flexural resistance}

According to Eurocode 3 [3], the joint plastic flexural resistance is evaluated as follows:

$M_{\mathrm{j} . \mathrm{Rd}}=\sum_{r=1}^{2} h_{r} F_{\mathrm{tr} . \mathrm{Rd}}$

where $h_{r}$ is the distance of the $r$-th bolt row from the centre of compression, located at the mid thickness of the beam flange in compression and $F_{\text {tr.Rd }}$ is the effective tension resistance of bolt row $r$. As the overall connection behaviour is dominated by the end plate and bolts, the computation of $F_{\text {tr.Rd }}$ relies on the T-stub idealization of the tension zone that can fail according (a)

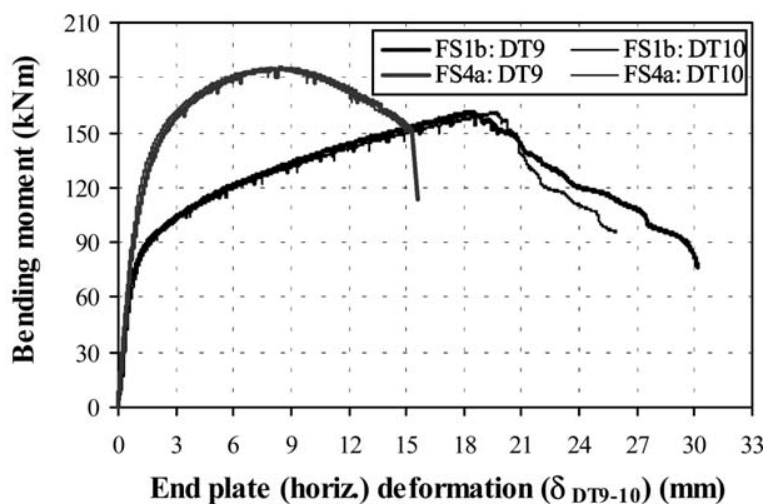

(b)

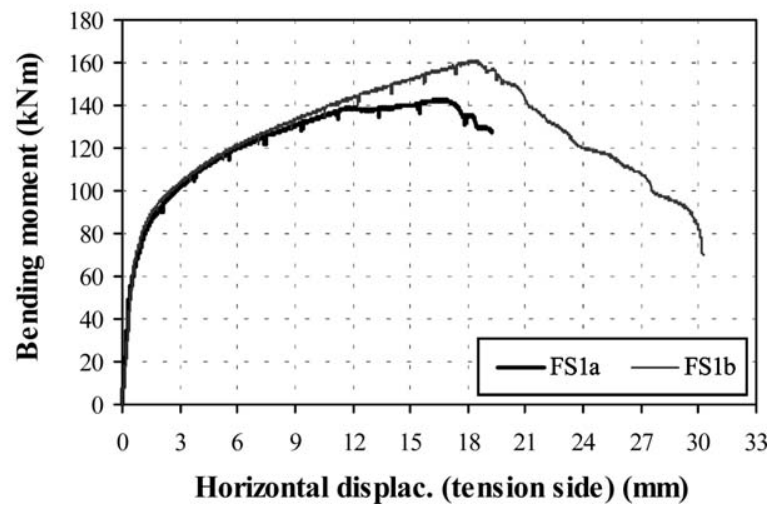

Fig. 16. End plate deformation in the tension zone for several specimens. (a) Comparison of the responses for the two devices (DT9, DT10) for tests FS1b and FS4a. (b) Comparison of the responses for the two tests from series FS1 (deformations from DT9).

to three possible plastic collapse mechanisms. Type-1 mechanism is characterized by complete flange yielding, Type- 2 corresponds to bolt failure with flange 


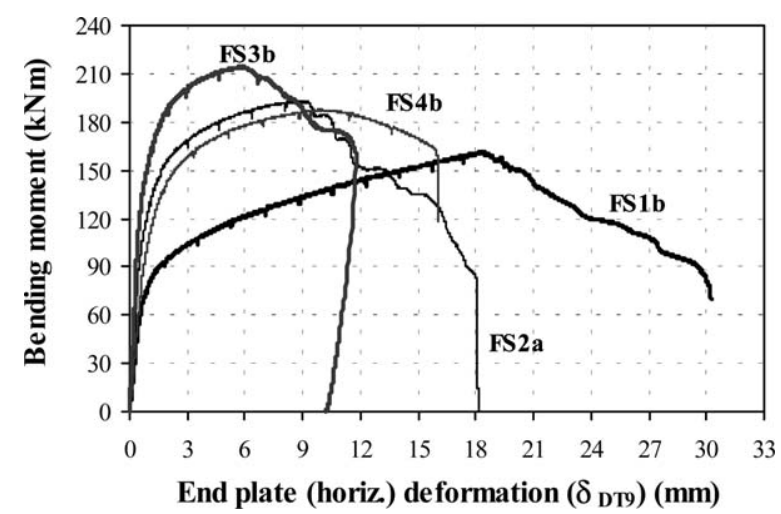

Fig. 17. Comparison of the moment-end plate deformation curves for the four test series.

yielding and the third collapse mechanism involves bolt failure only.

Application of the procedure detailed in [3] provides the results presented in Table 9. It is worth mentioning

(a)

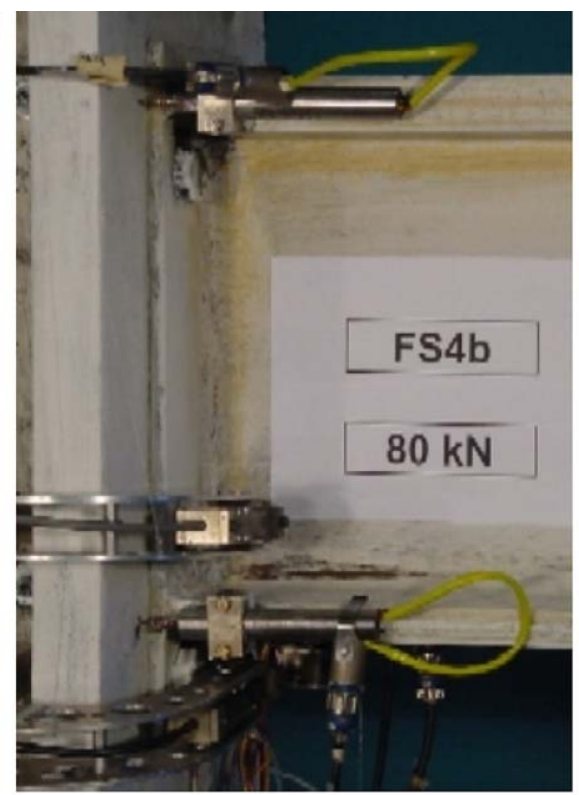

(c)

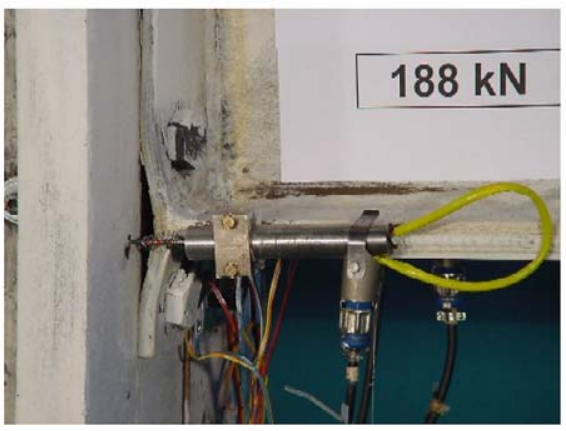

that the predicted yield line patterns (double curvature for the bolt row located at the end plate extension and side yielding near the beam flange) are in line with the experimental observations (cf. Fig. 22 for the inner bolt row, for instance). By comparing the code predictions with the experiments, they are within the knee-range bounds but below the experimental values of flexural resistance.

\subsection{Initial rotational stiffness}

The initial rotational stiffness of the tested joints is given by [3]:

$$
S_{\mathrm{j} . \mathrm{ini}}=\frac{z^{2}}{\sum_{i} \frac{1}{k_{i}}}
$$

whereby the lever arm $z$ is taken as equal to the distance from the centre of compression to a point midway between the two bolt rows in tension and $k_{i}$ is the

(b)

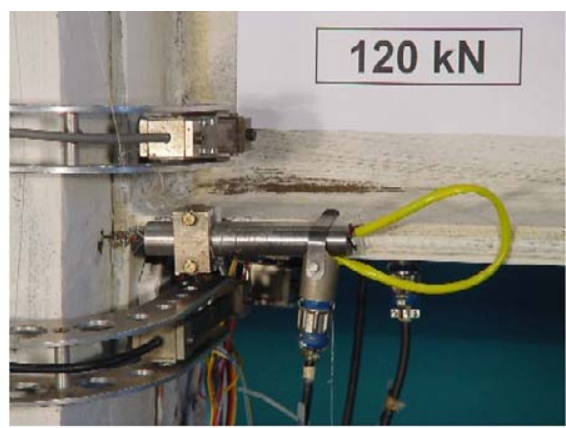

(d)

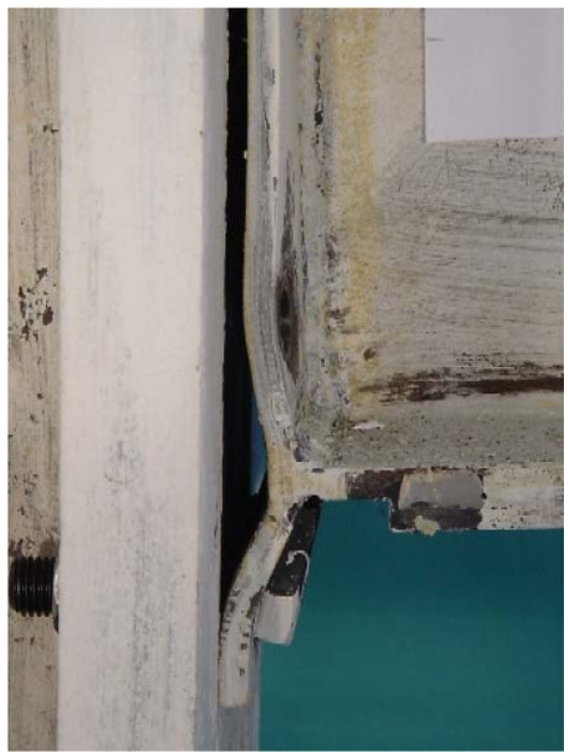

Fig. 18. Evolution of the end plate deformations until failure conditions for test series FS4b. (a) General view; load $=80 \mathrm{kN}$ (theoretical elastic limit; elastic branch of the $M-\phi$ curve). (b) Tension zone; load $=162 \mathrm{kN}$ (post-limit branch of the $M-\phi$ curve). (c) Load $=188 \mathrm{kN}$ (maximum load attained during the test). (b) Tension zone; Load $=162 \mathrm{kN}$ (post-limit branch of the $M-\phi$ curve). (c) Load $=188 \mathrm{kN}$ (maximum load attained during the test). (d) Tension zone; collapse conditions. 
(a)

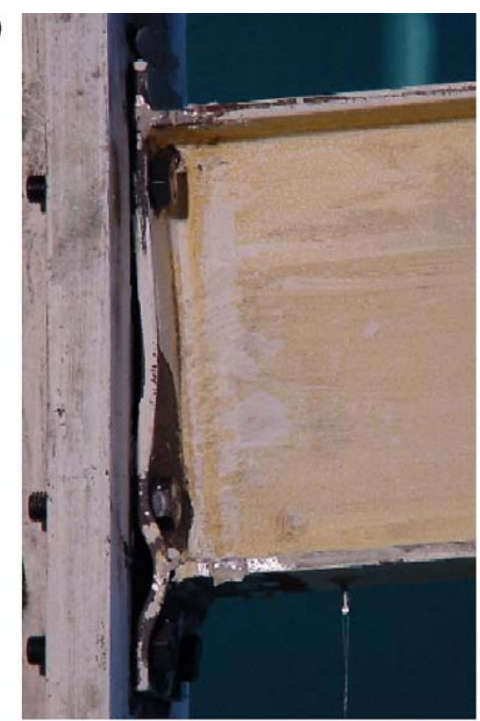

(b)

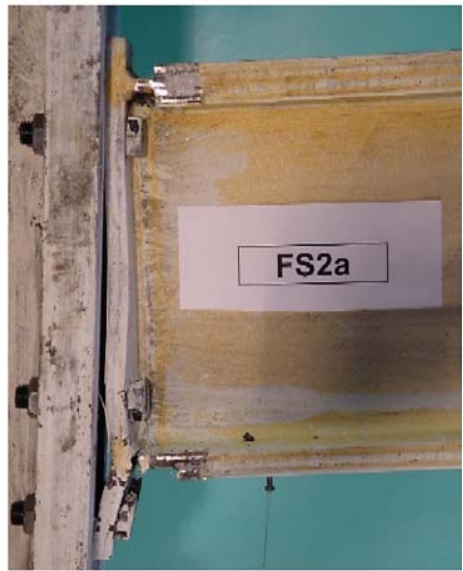

(c)

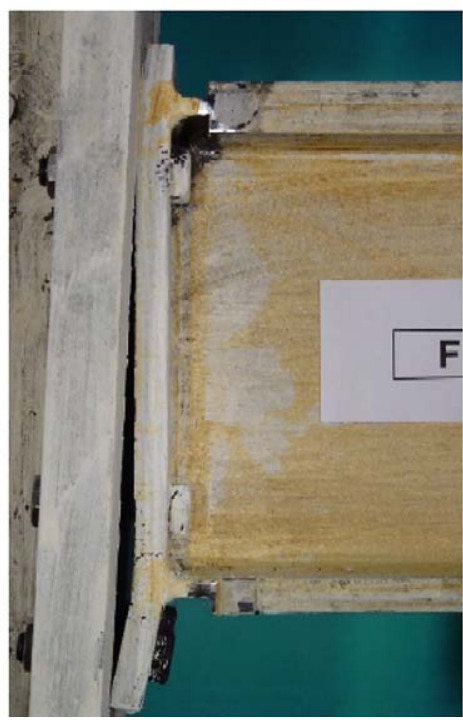

Fig. 19. Comparison of the end plate deformations at failure conditions for test series FS1-3. (a) Specimen FS1a. (b) Specimen FS2a. (c) Specimen FS3b.

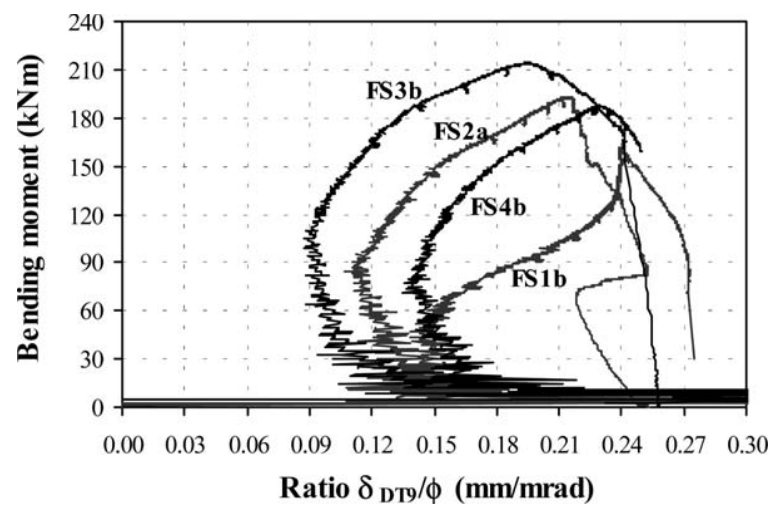

Fig. 20. Comparison of the ratio end plate deformation vs. connection rotation for the four test series.

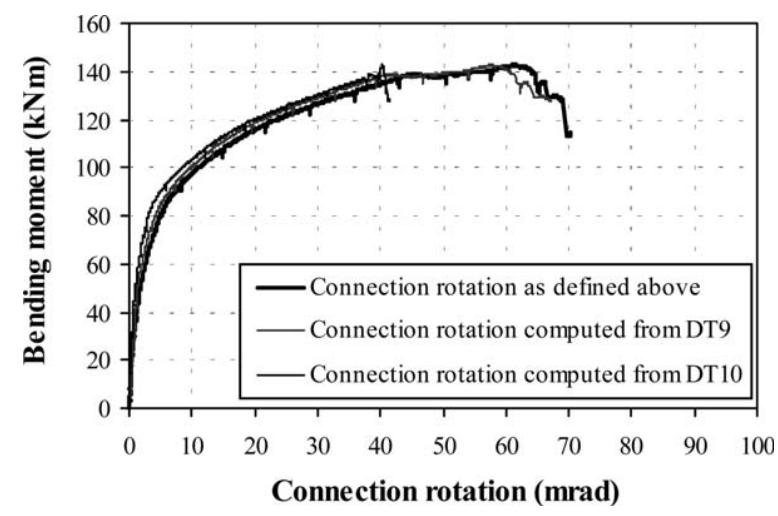

Fig. 21. Comparison of the moment-rotation curve for test FS1a by using alternative definitions of connection rotation. 
(a)

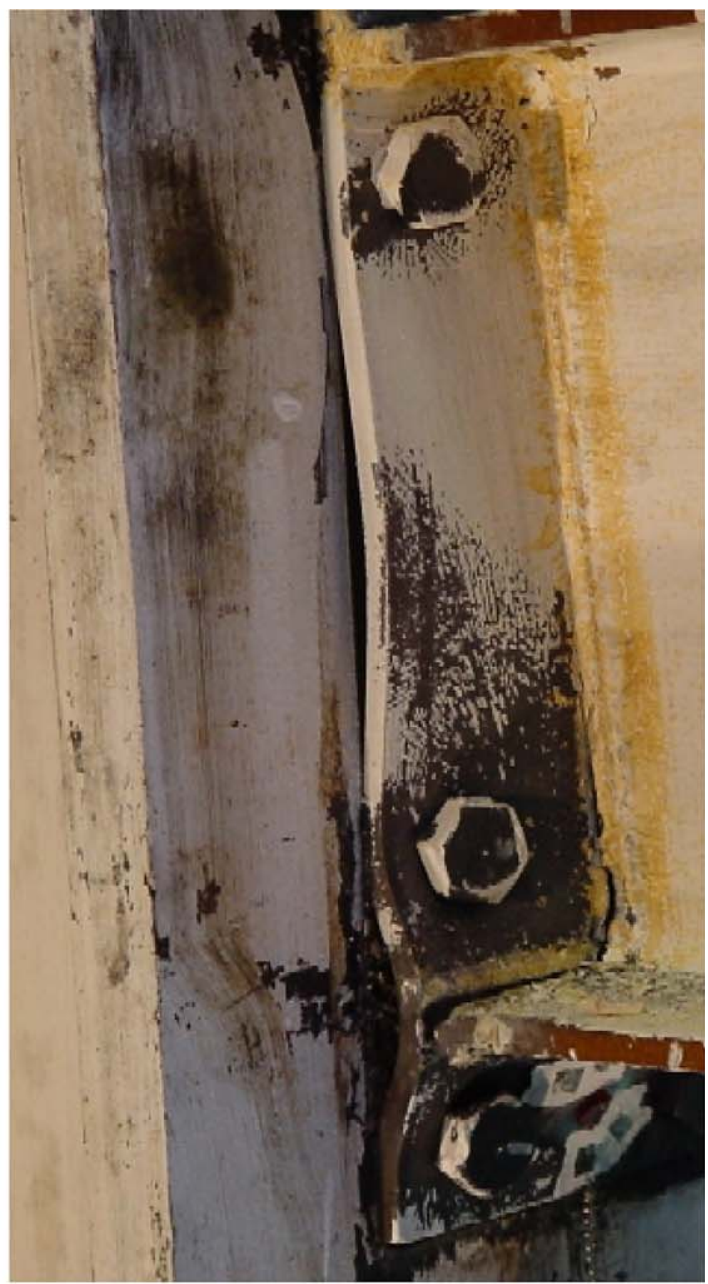

(b)

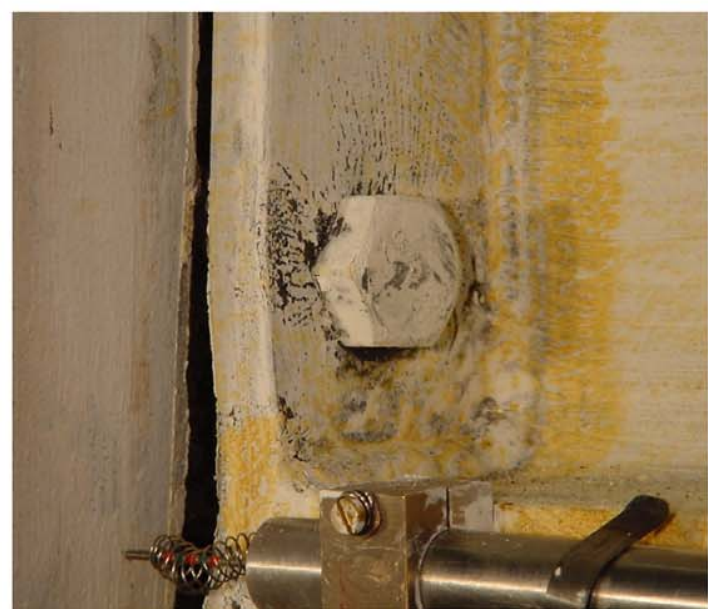

Fig. 22. Yield line patterns around the inner tension bolt at collapse conditions (e.g. specimens FS1b and FS2b). (a) Specimen FS1b. (b) Specimen FS2b.

stiffness coefficient for joint component $i$. For a singlesided beam-to-column joint with bolted end plate connection, the stiffness coefficients that have to be taken into account are those related to the column web in

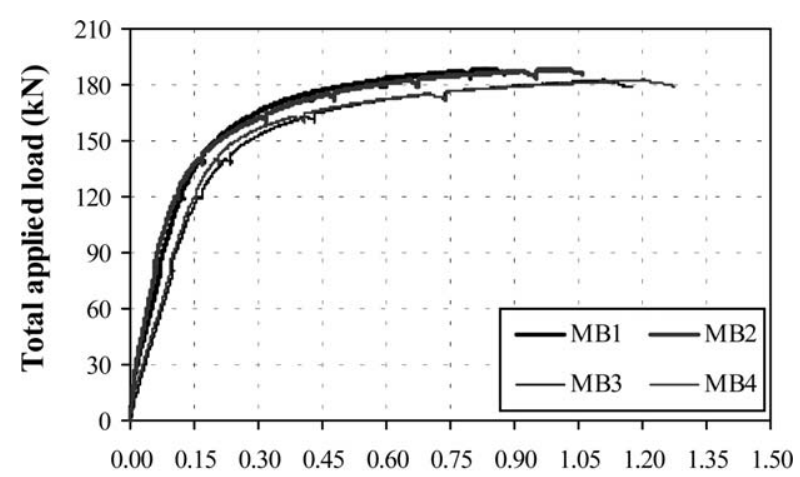

(Tension) Bolt elongation (mm)

Fig. 23. Bolt elongation behaviour (e.g. specimen FS4b).

shear $\left(k_{1}\right)$ and in transverse compression $\left(k_{2}\right)$ and an equivalent stiffness coefficient $k_{\text {eq }}$ that represents the basic components related to the bolt rows in tension. The latter coefficient is evaluated as follows [3]:

$k_{\mathrm{eq}}=\frac{\sum_{r} k_{\mathrm{eff}, r} h_{r}}{z}$

with:

$k_{\mathrm{eff}, r}=\frac{1}{\sum_{i} \frac{1}{k_{i, r}}}$.

and is based on the stiffness coefficients for the column web in tension, the column flange in bending, the end plate in bending and the bolts in tension. $k_{i, r}$ is the stiffness coefficient representing component $i$ relative to bolt row $r$. For simplicity, $z$ is taken as equal to the distance from the centre of compression to a point midway between the two bolt rows in tension [3].

Table 10 sets out the predicted values for the initial stiffness and compares them with the experiments. The ratio between the predicted values and the experiments shows that Eurocode [3] overestimates this property. The differences may derive from the fact that the expression as presented in the code was calibrated for a certain range of joints. The particular joints that were tested were not 'balanced', i.e. there was a much weaker component than the remaining. This situation is unlikely to occur in common joints for which the expression was calibrated.

\subsection{Rotation capacity}

The experimental values of rotation capacity and corresponding ductility indexes for the various tests are set out in Table 11. It can be easily seen that test FS1, which employs a thinner end plate and steel grade S355, presents higher ductility than the remaining tests. 
(a)

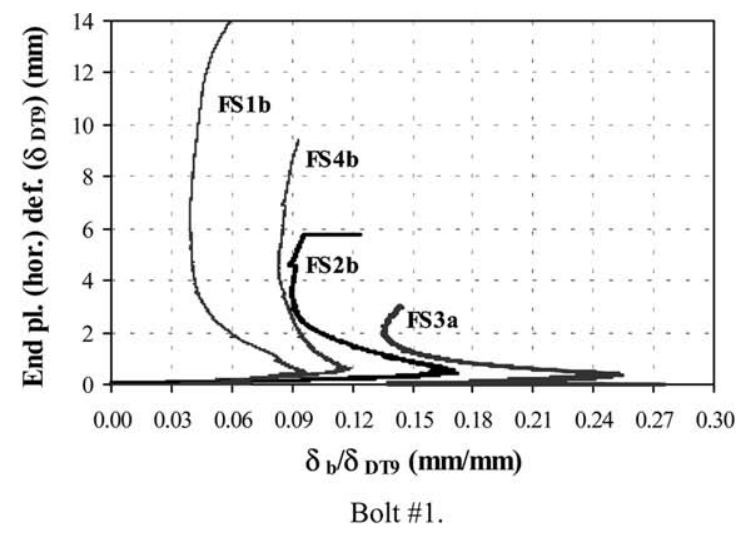

(b)

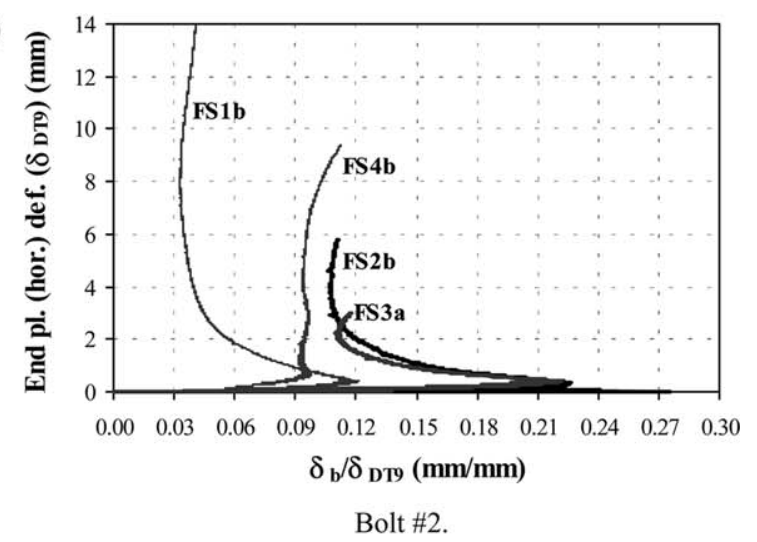

(c)

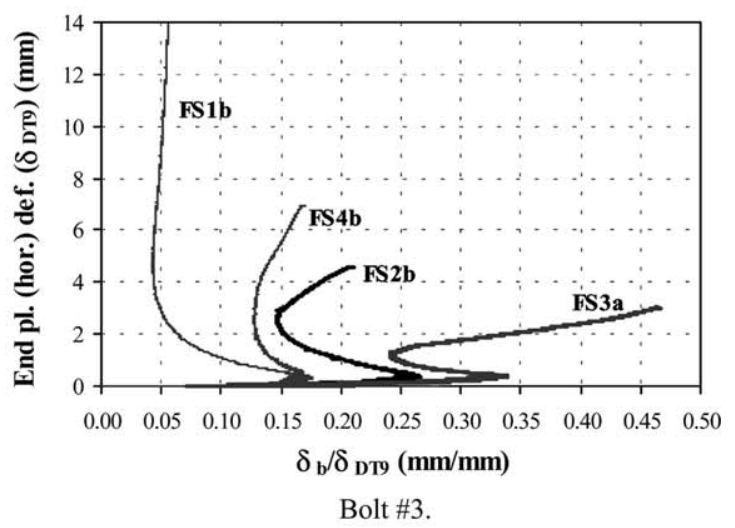

(d)

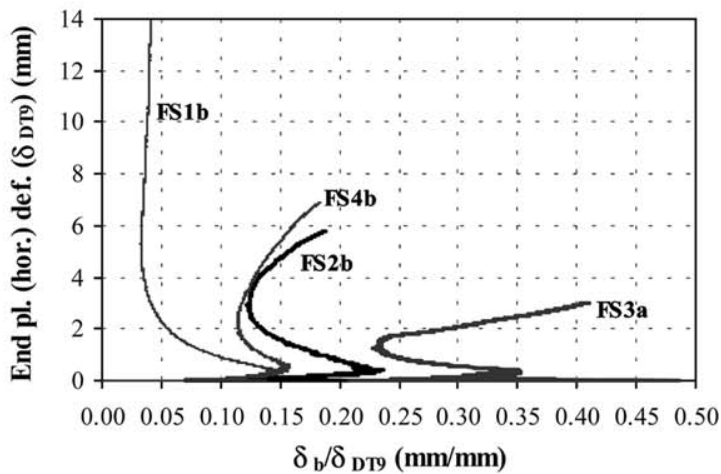

Bolt \#4.

Fig. 24. Comparison of the "nondimensional" bolt elongation behaviour for the four specimen types. (a) Bolt \#1. (b) Bolt \#2. (c) Bolt \#3. (d) Bolt \#4.
Application of the Eurocode 3 guidelines to the characterization of the rotation capacity [3] - cf. Section. 1 - shows that the first condition is guaranteed for all specimens (the joint moment resistance is governed by the resistance of the end plate in bending), whilst the second condition (Eq. (1)) is only fulfilled for specimens FS1 (Table 12). Though these recommendations are only valid for steel grades up to S460, they were also applied to series FS4 that includes end plates from grade $\mathrm{S} 690$.

Since the various specimens were designed to concentrate most of the deformability on the tension zone (end plate side) that is idealized as a T-stub, the analysis of this elemental part as a standalone configuration in terms of deformation behaviour is also carried out. The experimental deformation behaviour of this region is characterized from the LVDTs readings (Table 13) and is directly related to the T-stub deformation. The values taken for further considerations are those from LVDT DT9. The force acting at the T-stub web, $F_{0}$, is computed as follows:

$F_{0}=\frac{M}{h_{\mathrm{b}}-t_{\mathrm{fb}}}$

whereby $h_{\mathrm{b}}$ is the beam section height and $t_{\mathrm{fb}}$ is the beam flange thickness. The corresponding component ductility indexes are also evaluated (Table 13). They reflect the same tendency as the previous results for global rotations (Table 11).

Naturally, the T-stub tested in isolation does not completely reflect this real behaviour when inserted into a more complex joint. However, the results for the isolated T-stub must be comparable to those from the joint for the T-stub model for the tension region to be valid. Bearing that in mind, a comparative analysis of the average ductility indexes is summarized in Table 14. These average values are those corresponding to $M_{\mathrm{j} . \mathrm{Rd}}$ or $F_{0 . \text { Rd }}$, as appropriate. The upper and lower variations of the indexes $\left(\psi_{\text {inf }}\right.$ and $\left.\psi_{\text {sup }}\right)$ are also indicated as a percentage value. The results from the corresponding isolated T-stubs from reference [15] are also reported. Although the experimental definition of the knee-range bounds is very sensitive, particularly the lower bound, the results extracted from the global joint rotation and the end plate T-stub for rotation capacity are within acceptable agreement. Further comparisons with the isolated T-stubs (where possible) confirms this statement.

\section{Conclusions}

Tests on 8 extended end plate moment connections were conducted under static loading. All specimens were designed to trigger failure in the end plate rather 
Table 9

Evaluation of the resistance of the test specimens (the experimental values correspond to the average of the two tests per connection detail)

\begin{tabular}{|c|c|c|c|c|c|c|c|c|}
\hline \multirow[t]{2}{*}{ Test ID } & \multicolumn{3}{|l|}{ Row 1} & \multicolumn{3}{|l|}{ Row 2} & \multirow{2}{*}{$\begin{array}{l}M_{\mathrm{j} . \mathrm{Rd}} \\
(\mathrm{kNm})\end{array}$} & \multirow{2}{*}{$\begin{array}{l}\text { Ratio } \\
\text { [theory/experiments }\end{array}$} \\
\hline & $h_{1}(\mathrm{~mm})$ & $F_{t 1 . \mathrm{Rd}}(\mathrm{kN})$ & Plastic mode & $\mathrm{h}_{2}(\mathrm{~mm})$ & $F_{\mathrm{t} 2 \cdot \mathrm{Rd}}(\mathrm{kN})$ & Plastic mode & & \\
\hline FS1 & 334.52 & 83.86 & Type-1 & 244.49 & 202.34 & Type-1 & 77.52 & 0.72 \\
\hline FS2 & 335.26 & 176.07 & Type-1 & 245.28 & 297.87 & Type-2 & 132.09 & 0.79 \\
\hline FS3 & 335.34 & 274.06 & Type-2 & 245.20 & 389.01 & Type-2 & 187.29 & 1.03 \\
\hline FS4 & 334.76 & 161.16 & Type-1 & 244.81 & 287.94 & Type-2 & 124.44 & 0.76 \\
\hline
\end{tabular}

Table 10

Evaluation of the initial rotational stiffness of the test specimens (the experimental values correspond to the average of the two tests per connection detail)

\begin{tabular}{lclllllll}
\hline Test ID & $\begin{array}{l}k_{\text {eff.1 }} \\
(\mathrm{kN} / \mathrm{mm})\end{array}$ & $\begin{array}{l}k_{\text {eff.2 }} \\
(\mathrm{kN} / \mathrm{mm})\end{array}$ & $\begin{array}{l}k_{\text {eq }} \\
(\mathrm{kN} / \mathrm{mm})\end{array}$ & $\begin{array}{l}k_{1} \\
(\mathrm{kN} / \mathrm{mm})\end{array}$ & $\begin{array}{l}k_{2} \\
(\mathrm{kN} / \mathrm{mm})\end{array}$ & $\begin{array}{l}z \\
(\mathrm{~mm})\end{array}$ & $\begin{array}{l}S_{\text {j.ini }} \\
(\mathrm{kNm} / \mathrm{mrad})\end{array}$ & $\begin{array}{l}\text { Ratio } \\
{[\text { theory/experiments] }}\end{array}$ \\
\hline FS1 & 225.023 & 333.57 & 541.95 & 2718.64 & 4867.62 & 289.51 & 34.66 & 1.98 \\
FS2 & 375.03 & 453.37 & 816.22 & 2717.60 & 4983.72 & 289.62 & 46.76 & 2.06 \\
FS3 & 2453.12 & 496.04 & 942.50 & 2711.5 & 5052.06 & 290.27 & 51.76 & 2.31 \\
FS4 & 202.18 & 315.65 & 500.25 & 2710.23 & 4857.34 & 290.41 & 32.77 & 1.97 \\
\hline
\end{tabular}

Table 11

Evaluation of the joint ductility indexes

\begin{tabular}{|c|c|c|c|c|c|c|c|c|c|c|c|}
\hline \multirow[t]{2}{*}{ Test ID } & \multicolumn{3}{|c|}{$\begin{array}{l}\text { Rotation values at the } \mathrm{KR} \\
\text { [mrad] }\end{array}$} & \multicolumn{4}{|c|}{ Ductility indexes at $M_{\max }$} & \multicolumn{4}{|c|}{ Ductility indexes at failure } \\
\hline & $\phi_{\mathrm{KR} . \mathrm{inf}}$ & $\phi_{M_{\mathrm{Rd}}}$ & $\phi_{\mathrm{KR} \text {.sup }}$ & $\phi_{M_{\max }}$ & $\psi_{\mathrm{j} . \mathrm{inf}}$ & $\psi_{\mathrm{j} . \mathrm{Rd}}$ & $\psi_{\mathrm{j} \text {.sup }}$ & $\phi_{C d}$ & $\psi_{\mathrm{j} . \mathrm{inf}}$ & $\psi_{\mathrm{j} . \mathrm{Rd}}$ & $\psi_{\mathrm{j} \text {.sup }}$ \\
\hline FS1a & 3.0 & 5.81 & 17.5 & 61.55 & 20.52 & 10.59 & 3.52 & 68.91 & 22.97 & 11.86 & 3.94 \\
\hline FS1b & 4.2 & 6.49 & 25.0 & 77.05 & 18.35 & 11.87 & 3.08 & 111.22 & 26.48 & 17.14 & 4.45 \\
\hline $\mathrm{FS} 2 \mathrm{a}$ & 6.5 & 7.08 & 20.0 & 41.72 & 6.42 & 5.89 & 2.09 & 82.88 & 12.75 & 11.71 & 4.14 \\
\hline FS2b & 6.3 & 7.74 & 20.5 & 40.30 & 6.40 & 5.21 & 1.97 & 60.89 & 9.67 & 7.87 & 2.97 \\
\hline FS3a & 5.5 & 7.42 & 15.0 & 25.00 & 4.55 & 3.37 & 1.67 & 42.76 & 7.77 & 5.75 & 2.85 \\
\hline FS3b & 5.5 & 8.94 & 18.0 & 29.99 & 5.45 & 3.35 & 1.67 & 48.74 & 8.86 & 5.45 & 2.71 \\
\hline FS4a & 6.9 & 10.24 & 21.0 & 37.70 & 5.46 & 3.69 & 1.80 & 61.69 & 8.94 & 6.04 & 2.94 \\
\hline FS4b & 6.9 & 9.53 & 21.6 & 43.85 & 6.36 & 4.60 & 2.03 & 64.24 & 9.31 & 6.74 & 2.97 \\
\hline
\end{tabular}

Table 12

Verification of the recommendations for rotation capacity

\begin{tabular}{llll}
\hline Test ID & $t_{\mathrm{p}}(\mathrm{mm})$ & $\begin{array}{l}\text { Maximum } \\
t_{\mathrm{p}}(\mathrm{mm})\end{array}$ \\
\hline FS1 & 10.40 & 11.80 & Yes \\
FS2 & 15.01 & 11.75 & No \\
FS3 & 20.02 & 11.76 & No \\
FS4 & 10.06 & 8.25 & No \\
\hline
\end{tabular}

than in the beam or the column. The following conclusions can be drawn from the test programme:

1. The joint moment resistance increases with an increase of end plate thickness and with the yield stress of the plate.

2. The joint initial rotational stiffness also increases with the end plate thickness, but the sensitivity to

Table 13

Evaluation of the components end plate and bolts ductility indexes

\begin{tabular}{|c|c|c|c|c|c|c|c|c|c|c|c|}
\hline \multirow[t]{2}{*}{ Test ID } & \multicolumn{3}{|c|}{$\begin{array}{l}\text { Deformation values at the KR } \\
{[\mathrm{mm}]}\end{array}$} & \multicolumn{4}{|c|}{ Ductility indexes at $F_{0 \cdot \max }$} & \multicolumn{4}{|c|}{ Ductility indexes at failure } \\
\hline & $\Delta_{\mathrm{KR} \text {.inf }}$ & $\Delta_{F_{0 . \mathrm{Rd}}}$ & $\Delta_{\text {KR.sup }}$ & $\Delta_{F_{0 \text { max }}}$ & $\psi_{0 . \text { inf }}$ & $\psi_{0 . \mathrm{Rd}}$ & $\psi_{0 . \text { sup }}$ & $\Delta_{\max }$ & $\psi_{0 . \text { inf }}$ & $\psi_{0 . \mathrm{Rd}}$ & $\psi_{0 . \text { sup }}$ \\
\hline FS1a & 0.50 & 0.70 & 3.86 & 16.56 & 33.13 & 23.66 & 4.29 & 19.28 & 38.56 & 27.54 & 4.99 \\
\hline FS1b & 0.90 & 1.00 & 4.40 & 18.44 & 20.48 & 18.44 & 4.19 & 30.23 & 33.59 & 30.23 & 6.87 \\
\hline FS2a & 0.70 & 0.80 & 2.74 & 8.98 & 12.83 & 11.23 & 3.28 & 18.06 & 25.80 & 22.58 & 6.59 \\
\hline $\mathrm{FS} 2 \mathrm{~b}$ & 0.80 & 0.90 & 2.92 & 9.01 & 11.26 & 10.01 & 3.08 & 14.55 & 18.19 & 16.17 & 4.98 \\
\hline FS3a & 0.47 & 0.75 & 1.73 & 4.75 & 10.11 & 6.33 & 2.75 & 10.34 & 22.00 & 13.79 & 5.98 \\
\hline FS3b & 0.49 & 0.75 & 2.39 & 5.87 & 11.98 & 7.83 & 2.46 & 11.77 & 24.02 & 15.69 & 4.92 \\
\hline FS4a & 1.15 & 1.30 & 5.35 & 8.47 & 7.36 & 6.51 & 1.58 & 15.28 & 13.28 & 11.75 & 2.86 \\
\hline FS4b & 0.96 & 1.30 & 3.44 & 10.04 & 10.46 & 7.72 & 2.92 & 16.03 & 16.69 & 12.33 & 4.66 \\
\hline
\end{tabular}


Table 14

Comparison of the components end plate and bolts and full joint average ductility indexes

\begin{tabular}{|c|c|c|c|c|c|c|c|c|c|c|c|c|c|}
\hline \multirow{3}{*}{$\begin{array}{l}\text { Test ID } \\
\text { FS1a }\end{array}$} & \multicolumn{4}{|c|}{ Joint ductility indexes } & \multicolumn{4}{|c|}{ End plate T-stub ductility indexes } & \multicolumn{5}{|c|}{ Isolated T-stubductility indexes } \\
\hline & \multicolumn{2}{|c|}{ Peak resist. } & \multicolumn{2}{|c|}{ Failure } & \multicolumn{2}{|c|}{ Peak resist. } & \multicolumn{2}{|c|}{ Failure } & \multirow{2}{*}{ WT7_M20 } & \multicolumn{2}{|c|}{ Peak resist. } & \multicolumn{2}{|c|}{ Failure } \\
\hline & 10.59 & $\begin{array}{l}-93 \% \\
+67 \%\end{array}$ & 11.86 & $\begin{array}{l}-93 \% \\
+67 \%\end{array}$ & 23.66 & $\begin{array}{l}-40 \% \\
+82 \%\end{array}$ & 27.54 & $\begin{array}{l}-40 \% \\
+82 \%\end{array}$ & & 10.83 & $-13 \%$ & 23.09 & $-13 \%$ \\
\hline FSlb & 11.87 & $\begin{array}{l}-54 \% \\
+74 \%\end{array}$ & 17.14 & $\begin{array}{l}-54 \% \\
+74 \%\end{array}$ & 18.44 & $\begin{array}{l}-11 \% \\
+77 \%\end{array}$ & 30.23 & $\begin{array}{l}-11 \% \\
+77 \%\end{array}$ & & & $+61 \%$ & & $+61 \%$ \\
\hline FS2a & 5.89 & $\begin{array}{l}-9 \% \\
+65 \%\end{array}$ & 11.71 & $\begin{array}{l}-9 \% \\
+65 \%\end{array}$ & 11.23 & $\begin{array}{l}-14 \% \\
+71 \%\end{array}$ & 22.58 & $\begin{array}{l}-14 \% \\
+71 \%\end{array}$ & - & & & & \\
\hline FS2b & 5.21 & $\begin{array}{l}-23 \% \\
+62 \%\end{array}$ & 7.87 & $\begin{array}{l}-23 \% \\
+62 \%\end{array}$ & 10.01 & $\begin{array}{l}-13 \% \\
+69 \%\end{array}$ & 16.17 & $\begin{array}{l}-13 \% \\
+69 \%\end{array}$ & & & & & \\
\hline FS3a & 3.37 & $\begin{array}{l}-35 \% \\
+50 \%\end{array}$ & 5.75 & $\begin{array}{l}-35 \% \\
+50 \%\end{array}$ & 6.33 & $\begin{array}{l}-60 \% \\
+57 \%\end{array}$ & 13.79 & $\begin{array}{l}-60 \% \\
+57 \%\end{array}$ & - & & & & \\
\hline FS3b & 3.35 & $\begin{array}{l}-63 \% \\
+50 \%\end{array}$ & 5.45 & $\begin{array}{l}-63 \% \\
+50 \%\end{array}$ & 7.83 & $\begin{array}{l}-53 \% \\
+69 \%\end{array}$ & 15.69 & $\begin{array}{l}-53 \% \\
+69 \%\end{array}$ & & & & & \\
\hline FS4a & 3.69 & $\begin{array}{l}-48 \% \\
+51 \%\end{array}$ & 6.04 & $\begin{array}{l}-48 \% \\
+51 \%\end{array}$ & 6.51 & $\begin{array}{l}-13 \% \\
+76 \%\end{array}$ & 11.75 & $\begin{array}{l}-13 \% \\
+76 \%\end{array}$ & WT57_M20 & 12.39 & $+33 \%$ & 18.22 & $+33 \%$ \\
\hline FS4b & 4.60 & $\begin{array}{l}-38 \% \\
+56 \%\end{array}$ & 6.74 & $\begin{array}{l}-38 \% \\
+56 \%\end{array}$ & 7.72 & $\begin{array}{l}-35 \% \\
+62 \%\end{array}$ & 12.33 & $\begin{array}{l}-35 \% \\
+62 \%\end{array}$ & & & $+58 \%$ & & $+58 \%$ \\
\hline
\end{tabular}

the thickness variation is not as noticeable as for resistance; the steel grade has little influence if any on this property.

3. The joint post-limit rotational stiffness is identical for all specimens, i.e. the variation with end plate thickness or steel grade is not significant.

4. The Eurocode 3 [3] proposals give safe approaches for the prediction of the joint resistance but overestimates the joint initial stiffness in this particular case.

5. The available rotation capacity and hence the joint ductility decreases with the plate thickness (series FS1, FS2 and FS3) and with the plate steel grade (FS1 and FS4).

6. In terms of the verification of sufficient rotation capacity, Eurocode 3 [3] gives safe criteria but perhaps too conservative. For instance, in terms of overall rotation capacity, specimens from series FS2 and FS4 exhibit rotation values of $40 \mathrm{mrad}$.

7. A clear code statement on the required rotation capacity is desirable to establish whether the available ductility is sufficient or not, particularly for high strength steels.

8. Special attention should be paid to the nut stripping phenomena that was observed rather often in the tests. This is a brittle failure mode and was observed in tests FS2 and FS3. The combination of $15 \mathrm{~mm}$ end plates with M20 bolts is quite frequent in steel construction and for this case a brittle failure has occurred.

The experimental investigation presented in this paper provides accurate information on the characterization of the end plate failure modes and corresponding ductility levels. Some of the parameters affecting the rotation capacity (plate thickness and steel grade) have been highlighted and their influence on the overall behaviour of the connection has been qualitatively and quantitatively assessed. The next logical step forward is the development of numerical models to investigate this topic further and open the way to simple analytical procedures for estimation of rotation capacity.

\section{Acknowledgments}

Financial support from the Portuguese Ministry of Science and Higher Education (Ministério da Ciência e Ensino Superior) under contract grants from PRODEP and FCT (Grant SFRH/BD/5125/2001) for Ana M. Girão Coelho is gratefully acknowledged

The assistance provided by the staff of the Stevin Laboratory of the Faculty of Civil Engineering and Geosciences, Delft University of Technology, in making the test specimens available and their support in conducting the tests is most appreciated.

\section{References}

[1] Zoetemeijer P. A design method for the tension side of statically loaded bolted beam-to-column connections. Heron 1974;20(1): $1-59$.

[2] Yee YL, Melchers RE. Moment-rotation curves for bolted connections. Journal of Structural Engineering ASCE 1986;112(3): 615-635.

[3] European Committee for Standardization (CEN). PrEN 1993-18:2003, Eurocode 3: Design of steel structures. Part 1.8: Design of joints, Stage 49 draft, May 2003, Brussels; 2003.

[4] Packer JA, Morris LJ. A limit state design method for the tension region of bolted beam-to-column connections. The Structural Engineer 1977;55(10):446-58. 
[5] Jaspart J.P. Etude de la semi-rigidité des noeuds poutre-colonne et son influence sur la resistance et la stabilité des ossatures en acier. $\mathrm{PhD}$ thesis (in French). University of Liège, Liège; 1991.

[6] Bursi OS, Jaspart JP. Benchmarks for finite element modelling of bolted steel connections. Journal of Constructional Steel Research 1997;43(1):17-42.

[7] Faella C, Piluso V, Rizzano G. Experimental analysis of bolted connections: snug versus preloaded bolts. Journal of Structural Engineering ASCE 1998;124(7):765-74.

[8] Gebbeken N, Wanzek T. Benchmark experiments for numerical simulations of T-stubs. In: K. S. Virdi (editor), Numerical simulation of semi-rigid connections by the finite element method, COST C1. Report of working group 6-Numerical simulation. Brussels; 1999. p. 61-70.

[9] Swanson JA, Leon RT. Bolted steel connections: tests on T-stub components. Journal of Structural Engineering ASCE 2000;126(1):50-6.

[10] Piluso V, Faella C, Rizzano G. Ultimate behavior of bolted Tstubs. I: theoretical model. Journal of Structural Engineering ASCE 2001;127(6):686-93.

[11] Piluso V, Faella C, Rizzano G. Ultimate behavior of bolted Tstubs. II: model validation. Journal of Structural Engineering ASCE 2001;127(6):694-704.

[12] Girão Coelho AM, Simões da Silva L. Numerical evaluation of the ductility of a bolted T-stub connection. In: Chan SL, Teng JG, Chung KF, editors. Advances in steel structures. Proceedings of the Third International Conference (ICASS'02) Hong Kong. 2002, p. 277-84.

[13] Girão Coelho AM, Bijlaard F, Simões da Silva L. On the deformation capacity of beam-to-column bolted connections. European Convention for Constructional Steelwork-Technical Comittee 10, Structural Connections (ECCS-TC10), Document ECCS-TWG 10.2-02-003; 2002.

[14] Girão Coelho AM, Bijlaard F, Simões da Silva L. On the behaviour of bolted end plate connections modelled by welded T-stubs. In: Lamas A, Simões da Silva L, editors. Steel strucutres. Proceedings of the Third European Conference (Eurosteel) Coimbra. 2002, p. 907-18.

[15] Girão Coelho AM, Bijlaard F, Gresnigt N, Simões da Silva L. Experimental assessment of the behaviour of bolted T-stub connections made up of welded plates. Journal of Constructional Steel Research 2004;60:269-311.

[16] Weynand K, Jaspart JP, Steenhuis M. The stiffness model of revised Annex $\mathbf{J}$ of Eurocode 3. In: Bjorhovde R, Colson A, Zandonini $\mathrm{R}$, editors. Connections in steel structures III. Proceedings of the Third international Workshop on connections Trento. 1995, p. 441-52.

[17] Zoetemeijer P. Summary of the research on bolted beam-to-column connections. Report 25-6-90-2. Delft University of Tech- nology, Faculty of Civil Engineering, Stevin Laboratory-Steel Structures; 1990

[18] Jaspart JP. Contributions to recent advances in the field of steel joints, Column bases and further configurations for bema-to-column joints and beam splices. Aggregation thesis. University of Liège, Liège; 1997.

[19] Swanson JA. Characterization of the strength, stiffness and ductility behavior of T-stub connections. PhD dissertation, Georgia Institute of Technology, Atlanta, USA; 1999.

[20] Faella C, Piluso V, Rizzano G. Structural semi-rigid connectionstheory, design and software. Boca Raton, USA: CRC Press; 2000.

[21] Kuhlmann U, Kuhnemund F. Rotation capacity of steel joints: verification procedure and component tests. In: Baniotopoulos $\mathrm{CC}$, Wald F, editors. The paramount role of joints into the reliable response of structures. Proceedings of the NATO advanced research workshop. Nato Science series. Dordrecht: Kluwer Academic Publishers; 2000, p. 363-72.

[22] Kuhlmann U, Kuhnemund F. Ductility of semi-rigid steel joints. In: Ivanyi M, editor. Stability and ductility of steel structures (SDSS 2002). Proceedings of the International Colloquium Budapest, Hungary. 2002, p. 363-70.

[23] Beg D, Zupančič, Vayas I. On the rotation capacity of moment connections. Journal of Constructional Steel Research 2004;60: 601-620.

[24] European Committee for Standardization (CEN). PrEN 10025:2000E: hot rolled products of structural steels, September 2000, Brussels; 2000.

[25] European Committee for Standardization (CEN). EN 10204:1995E: Metallic products, October 1995, Brussels; 1995.

[26] RILEM draft recommendation. Tension testing of metallic structural materials for determining stress-strain relations under monotonic and uniaxial tensile loading. Materials and Structures 1990;23:35-46.

[27] Gioncu V, Mazzolani FM. Ductility of seismic resistant steel structures. London: Spon Press; 2002.

[28] International Standard ISO 898-1:1999 (E). Mechanical properties of fasteners made of carbon steel and alloy steel-Part 1: bolts, screws and studs, August 1999, Switzerland; 1999.

[29] Weynand K. Sicherheits-und Wirtsschaftlichkeitsuntersuchungen zur anwendung nachgiebiger anschlüsse im stahlbau. $\mathrm{PhD}$ thesis (in German). University of Aachen, Aachen; 1996.

[30] Simões da Silva L, Santiago A, Vila Real P. Post-limit stiffness and ductility of end plate beam-to-column steel joints. Computers and Structures 2002;80:515-31.

[31] Kuhlmann U, Davison JB, Kattner M. Structural systems and rotation capacity. In: Maquoi R, editor. Control of the semirigid behaviour of civil engineering structural connections. Proceedings of the International Conference Liège, Belgium. 1998, p. $167-76$. 